Full length article

\title{
Development of low-alloyed and rare-earth-free magnesium alloys having ultra-high strength
}

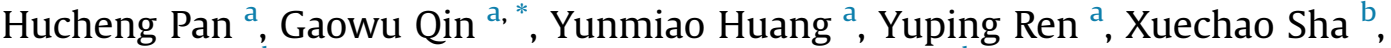 \\ Xiaodong Han ${ }^{\mathrm{b}}$, Zhi-Quan Liu ${ }^{\mathrm{c}}$, Caifu Li ${ }^{\mathrm{c}}$, Xiaolei Wu ${ }^{\mathrm{d}}$, Houwen Chen ${ }^{\mathrm{e}}$, Cong He ${ }^{\mathrm{e}}$, \\ Linjiang Chai ${ }^{\mathrm{f}}$, Yunzhi Wang ${ }^{\mathrm{g}, * * *}$, Jian-feng Nie ${ }^{\mathrm{e}, \mathrm{h}, * *}$ \\ ${ }^{a}$ Key Laboratory for Anisotropy and Texture of Materials (Ministry of Education), School of Materials Science and Engineering, Northeastern University, \\ Shenyang 110819, China \\ ${ }^{\mathrm{b}}$ Institute of Microstructure and Properties of Advanced Materials, Beijing University of Technology, Beijing 100124, China \\ ${ }^{\mathrm{c}}$ Institute of Metal Research, Chinese Academy of Sciences, Shenyang 110016, China \\ d State Key Laboratory of Nonlinear Mechanics, Institute of Mechanics, Chinese Academy of Sciences, Beijing 100190, China \\ e School of Materials Science and Engineering, Chongqing University, Chongqing 400044, China \\ ${ }^{\mathrm{f}}$ College of Materials Science and Engineering, Chongqing University of Technology, Chongqing 400054, China \\ ${ }^{g}$ Department of Materials Science and Engineering, The Ohio State University, 2041 N. College Rd., Columbus OH43210, USA \\ ${ }^{\mathrm{h}}$ Department of Materials Science and Engineering, Monash University, Victoria 3800, Australia
}

\section{A R T I C L E I N F O}

\section{Article history:}

Received 15 December 2017

Received in revised form

29 January 2018

Accepted 1 March 2018

Available online 7 March 2018

\section{Keywords:}

$\mathrm{Mg}$ alloy

Mechanical property

Dynamic recrystallization

Segregation

Strengthening mechanism

\begin{abstract}
A B S T R A C T
Developing ultra-high strength in rare-earth-free $\mathrm{Mg}$ alloys using conventional extrusion process is a great challenge. What is even more difficult is to achieve such a goal at a lower processing cost. In this work, we report a novel low-alloyed Mg-2Sn-2Ca alloy (in wt. \%) that exhibits tunable ultra-high tensile yield strength (360-440 MPa) depending on extrusion parameters. More importantly, there is little drop in mechanical properties of this alloy even when it is extruded at a speed several times higher than those used in the reported high strength Mg alloys. Examination of as-extruded microstructures of this $\mathrm{Ca}$ containing $\mathrm{Mg}$ alloy reveals that the ultra-high strength is mainly associated with the presence of surprisingly submicron matrix grains (down to $\sim 0.32 \mu \mathrm{m}$ ). The results suggest that the Ca addition promotes accumulations of the pyramidal dislocations, which eventually transform into the low angular grain boundaries (LAGBs). The high number density of LAGBs separate the $\alpha$-Mg matrix via either discontinuous dynamic recrystallization (DDRX) mechanism in the early stage or the continuous dynamic recrystallization (CDRX) mechanism in the later stage of extrusion, which effectively enhances the nucleation rates of the DRXed grains. More importantly, large amount of Ca segregation along LAGBs, accompanied with dynamically precipitated $\mathrm{Mg}_{2} \mathrm{Ca}$ nano-phases, are detected in the present nonseverely deformed samples. It is the combination of solute segregations and numerous $\mathrm{Mg}_{2} \mathrm{Ca}$ nanoprecipitates that contributes to the formation of the ultra-fine grains via pinning mechanism. The ultrafine grains size, Ca enrichment in most LAGBs, and residual $\mathrm{Mg}_{2} \mathrm{Ca}$ nano-precipitates would in turn contribute significantly to the enhancement of the yield strength of the as-extruded Mg-2Sn-2Ca (wt.\%) alloy. The low content of alloying elements and the fast one-step extrusion process render the present alloys low-cost and thus have great potential in large-scale industry applications.
\end{abstract}

@ 2018 Acta Materialia Inc. Published by Elsevier Ltd. All rights reserved.

\footnotetext{
* Corresponding author.

** Corresponding author. School of Materials Science and Engineering, Chongqing University, Chongqing 400044, China.

*** Corresponding author.

E-mail addresses: qingw@smm.neu.edu.cn (G. Qin), wang.363@osu.edu (Y. Wang), jianfeng.nie@monash.edu (J.-f. Nie).
}

\section{Introduction}

The growing concerns on the environmental problems keep inspiring us to develop novel magnesium alloys, which possess great potentials in aircraft and automobiles for energy saving due to the obvious advantages of low density ( $\sim 1 / 4$ of steel and $\sim 3 / 5$ of aluminum), high specific strength and ease of recycling [1,2]. However, the strengths of the current generation of Mg alloys are 
much lower than those of steels and Al-alloys [3-5]. Thus improving the absolute strength of Mg-alloys is a prerequisite for their wide-spread applications in the structural components [6-9].

Several Mg alloys with superior strength have been developed by incorporating precipitation hardening (such as Mg-Rare-Earth (RE)-based alloys [10,11]), grain refinement hardening (such as equal channel angular pressing, ECAP, high pressure torsion, HPT $[12,13])$ and texture hardening $[14,15]$. For example, the highest strength of $600 \mathrm{MPa}$ has been reported in Mg-2.5Zn-6.8Y (in wt.\%) alloy, processed by rapid solidification method [16]. High strength of $403 \mathrm{MPa}$ was also achieved in cast Mg-8.5Gd-2.3Y-1.8Ag-0.4Zr (in wt.\%), a Mg-RE alloy, processed simply by aging treatment due to precipitation of the nano-scale basal plate phases [17]. The key point is to introduce sufficiently high density of nano-sized strengthening phases and operate via the Orowan strengthening mechanism. In this sense, the Mg-RE alloys usually exhibit remarkable age-hardening response and promising yield strength levels of 400-500 MPa. However, the high cost and resource scarcity make the abundant usages of RE elements as the major solute additions unacceptable in commercial applications [11,18]. Moreover, manufacturing high strength $\mathrm{Mg}$ alloys usually works at quite low forming speed due to their poor formability, adding extra cost as compared to the Al counterparts.

On the other hand, the conventional RE-free Mg alloys, usually with much high contents of alloying elements, exhibit yield strengths lower than $350 \mathrm{MPa}$, in most cases lower than $300 \mathrm{MPa}$ $[19,20]$. In general, precipitation strengthening and grain refinement are considered as two effective strategies to improve strength of Mg alloys [21]. However, in the case of RE-free Mg alloys (such as $\mathrm{Mg}-\mathrm{Al}-, \mathrm{Mg}-\mathrm{Sn}$ - and Mg-Ca-based), their age-hardening responses are usually not yet significant $[20,22,23]$ because it is still a difficult challenge to achieve nano-dispersion of hetero-phase and homophase interfaces (e.g., nano-precipitates and grains) [24-27]. Fortunately, it is known that the grain refinement in $\mathrm{Mg}$ alloys contributes to the strengthening more significantly than the other alloy systems (such as $\mathrm{Al}$ alloys), according to their higher $k$ values in Hall-Petch relationship [28]. The ultrafine grains of $\alpha$-Mg matrix are thus considered to be necessary, but not yet well accomplished, for development of the high-strength Mg alloys. It is possible to utilize severe plastic deformation via HPT or ECAP mentioned above to obtain ultra-fine grains in Mg alloys [12,13], but the limited sizes of billets that can be produced by these processing techniques make their industrial applications remote. The inadequate strength of the RE-free Mg alloys is accordingly a well-known bottleneck that limits their widespread industrial usages. Therefore, it is becoming crucial to achieve ultra-fine grains and thus high strength in RE-free $\mathrm{Mg}$ alloys by utilizing the conventional continuous processing techniques such as rolling or extrusion.

In practical, the minimum grain sizes of RE-free $\mathrm{Mg}$ alloys produced by conventional process are usually around several micrometers $[25,26,29]$. For example, Sasaki et al. reported the average grain size of $\sim 2 \mu \mathrm{m}$ could be obtained in the as-extruded Mg-9.8Snbased (in wt.\%) alloy [25]. With help of the low-speed extrusion, the minimum grain size of $\mathrm{Mg}-10 \mathrm{Sn}-3 \mathrm{Al}-1 \mathrm{Zn}-0.1 \mathrm{Na}$ (in wt.\%) alloy can reach $\sim 1 \mu \mathrm{m}$, but the further refinement of matrix grains is even more difficult by conventional processes [26]. In this work, we found that a small amount addition of Ca to Mg-Sn alloy can induce high density of dislocations, sub-grain boundaries and numerous $\mathrm{Mg}_{2} \mathrm{Ca}$ nano-precipitates during conventional indirect extrusion. Interestingly, these $\mathrm{Mg}_{2} \mathrm{Ca}$ nano-precipitates and the sub-grain boundaries enriched by Ca can significantly restrict the growth of dynamically recrystallized grains, leading to submicron grain size (down to $\sim 0.32 \mu \mathrm{m}$ ) and also ultra-high strength that is tunable depending on extrusion parameters. The wrought Mg-2Sn-2Ca (in wt.\%, named as TX22) alloy can exhibit an ultra-high absolute strength, a yield strength (YS) of $443 \mathrm{MPa}$, or a good strengthductility balance, e.g., a YS of $358 \mathrm{MPa}$ and a room temperature elongation to facture of $\sim 8.9 \%$.

\section{Experimental}

Mg-2Sn-2Ca alloy was prepared by melting the commercial pure $\mathrm{Mg}$ (99.90 wt\%), Sn (99.95 wt\%) and Ca (99.90wt\%) in the crucible resistance furnace and pouring the melt into the preheated mould $\left(350^{\circ} \mathrm{C}\right)$ with diameter of $50 \mathrm{~mm}$ under the protection of mixture gas of $\mathrm{CO}_{2}$ and $\mathrm{SF}_{6}(100: 1)$. The starting cast billet was homogenized at $500{ }^{\circ} \mathrm{C}$ for $24 \mathrm{~h}$ and water quenched. Before indirect extrusion, billets with $45 \mathrm{~mm}$ in diameter and $100 \mathrm{~mm}$ in length were pre-heated at $220-320^{\circ} \mathrm{C}$ for $0.5 \mathrm{~h}$ in a resistance furnace. Indirect extrusions were then conducted at the $220-320^{\circ} \mathrm{C}$, respectively, with an extrusion ratio of 20 and ram speeds of $0.3-1.3 \mathrm{~mm} / \mathrm{s}$.

The tensile tests were conducted with the dog-bone specimens in gage length of $30 \mathrm{~mm}$ and the diameter of $5 \mathrm{~mm}$. Compression tests were conducted on the cylinder samples with height of $25 \mathrm{~mm}$ and diameter of $5 \mathrm{~mm}$. The samples were machined from the extrusion bars along extrusion direction (ED). The tensile properties were tested on Shimazu AG-X Plus at an initial tensile strain rate of $1 \times 10^{-3} \mathrm{~s}^{-1}$. The constituent phases of the as-cast, homogenized and as-extruded samples were identified by X-ray diffraction (XRD, Philips PW3040/60 X'Pert PRO with $\mathrm{Cu} \mathrm{K}_{\alpha}$ radiation). Microstructures of the specimens were examined by scanning electron microscopy (SEM, JEOL JSM-7001F), and SEM images were taken from cross sections of the extruded bar in the back scattered electron mode (BSE). For electron back scattering diffraction (EBSD) examinations, both the as-extruded samples and stage I - III samples were ground and electro-polished in the electrolyte $\left(80 \% \mathrm{C}_{2} \mathrm{H}_{5} \mathrm{OH}+20 \% \mathrm{HClO}_{4}\right)$ at $20 \mathrm{~V}$ for $\sim 30 \mathrm{~s}$ and at $30^{\circ} \mathrm{C}$. EBSD was conducted over cross-sections of the samples using the Zeiss Ultra 55 microscopy with step length of $0.08 \mu \mathrm{m}$. The EBSD was analyzed by the orientation imaging microscopy software (OIM, HKL-Channel 5). The misorientation angles between the adjacent grains are used to identify the low angular grain boundary (LAGB, $2^{\circ} \leq \theta \leq 15^{\circ}$ ) and high angular grain boundary (HAGB, $\theta \geq 15^{\circ}$ ), as indicated by red and black lines, respectively. The fraction of recrystallized grains was evaluated by the following method. If the boundary angles exceed $15^{\circ}$, the grains were considered to be recrystallized. The remaining grains with boundary angles lower than $15^{\circ}$ were considered as the un-recrystallized regions. The average grain sizes were estimated from the band contrast images by using the linear intercept method (with the software of nano-measurer).

Transmission electron microscopy (TEM, JEOL JEM-2100F) was used to characterize the crystal defects and nano-precipitates. Thin foils for TEM were prepared by mechanical polishing $(\sim 40 \mu \mathrm{m})$ and then ion beam thinning (GATAN, PIPS 691). TEM observation was then conducted with an accelerating voltage of $200 \mathrm{kV}$. Grain size in the alloys was measured by the linear intercept method from EBSD and TEM results. Moreover, the high-angle annular dark-field (HAADF) observation was also conducted by using an aberrationcorrected scanning transmission electron microscope (STEM, FEI Titan $G^{2} 60-300$ Chemi-STEM, equipped with a Cs probe corrector and a Super-X EDS with four windowless silicon-drift detectors), operated at $300 \mathrm{kV}$.

\section{Results}

\subsection{Mechanical properties}

The TX22 alloy was prepared by induction melting, 
homogenized at $500^{\circ} \mathrm{C}$ for $24 \mathrm{~h}$ and water-quenched, and then extruded at different temperatures in the range of $220-320^{\circ} \mathrm{C}$ (referred to as TX22-220 at $220^{\circ} \mathrm{C}$, for example, hereafter) and with ram speeds of $0.3-1.3 \mathrm{~mm} / \mathrm{s}$. Fig. 1 shows that the TX22-220 alloy, extruded with a ram speed of $0.3 \mathrm{~mm} / \mathrm{s}$, exhibits the high tensile YS of $443 \mathrm{MPa}$ and ultimate tensile strength (UTS) of $460 \mathrm{MPa}$, even though the elongation of $1.2 \%$ is not satisfactory. With a slight increase $\left(20^{\circ} \mathrm{C}\right)$ in the extrusion temperature, a $3.0 \%$ elongation to fracture is achieved in the TX22-240 alloy with its YS and UTS maintained at $420 \mathrm{MPa}$ and $435 \mathrm{MPa}$, respectively. The YSs, UTSs and elongations obtained at all extrusion temperatures from 220 to $320^{\circ} \mathrm{C}$ are listed in Table 1 and the corresponding engineering stress-strain curves are shown in Fig. 1a. In compression, the TX22220 and TX22-240 alloys exhibit the compressive yield strength (CYS) of $319 \mathrm{MPa}$ and $308 \mathrm{MPa}$, and the compression/tension yield ratio can be calculated to be 0.72 and 0.73 , respectively, as listed in Table 1 . The two extruded alloys show an lower asymmetry than those of the commercial Mg alloys having asymmetry ratio usually lower than 0.5, including the Mg-Mn and Mg-Al-Zn alloys [30,31]. As to the TX22-280 alloy, the compressive ultimate strength is $415 \mathrm{MPa}$ and CYS is $349 \mathrm{MPa}$, and its asymmetry ratio of 0.9 is obviously larger than that of the TX22-220 or TX22-240 alloy (Table 1).

The YSs and alloying contents of typical Mg alloys are compared, including present TX22 samples, and the reported RE-free Mg alloys involving Mg-Sn-Al-(Zn) [24-27], Mg-Al-Zn-(Zr) [32-37] and $\mathrm{Mg}-\mathrm{Al} / \mathrm{Zn}-\mathrm{Ca}-(\mathrm{Mn})$ [38-40], as well as the Mg-RE alloys involving the Mg-Gd-Y-Zr [41], Mg-Zn-Gd/Y-(Zr) [42,43] and Mg-Gd-Y-Zn-Zr [18,44,45], as shown in Fig. 1 b. Note that our newly developed Mg$0.1 \mathrm{wt} \% \mathrm{Ca}$ and Mg-1.0 wt \% Ca binary alloys that have superior YSs of 295-425 MPa are also included. The comparison shows that YSs of the present Ca-containing Mg alloy with tiny amount of solute additions ( $\leq 4 \mathrm{wt} \%$ ) can exceed the known strength limits of REfree $\mathrm{Mg}$ alloys, and are even comparable with those of reported RE-containing ( $\geq 15 \mathrm{wt} \%$ ) Mg alloys. The results clearly show the present Ca-containing Mg alloys are in a region of high strength and low alloying, beyond that of the other developed Mg alloys. Fig. 1c shows that although the YS of TX22 extruded at $220^{\circ} \mathrm{C}$ decreases slightly with increasing the ram speed (referred to as TX22-220-0.7, i.e., at $0.7 \mathrm{~mm} / \mathrm{s}$ ), it still keeps as high as $395-436 \mathrm{MPa}$ at ram speeds of $0.7-1.3 \mathrm{~mm} / \mathrm{s}$, which is superior to the recently reported YS of $410 \mathrm{MPa}$ in Mg-3.6Al-3.3Ca-0.4Mn (wt.\%) alloys extruded at a ram speed of $0.1 \mathrm{~mm} / \mathrm{s}$ [39]. More interestingly, distribution map of YS and ram speed in Fig. 1d further demonstrates that the present Ca-containing alloys can keep at a high-strength level under the relatively high extrusion speeds, jumping out of the "banana curve" region of the other developed RE-free Mg alloys.

\subsection{Microstructure characterization of as-extruded Mg alloy}

We will present detail microstructures to explain the superior mechanical properties of as-extruded TX22 alloys. The eutectic $\mathrm{Mg}_{2} \mathrm{Ca}$ and MgSnCa phases formed in as-cast TX22 alloy, as confirmed by XRD and SEM results, are partially dissolved after solution treatment at $500^{\circ} \mathrm{C}$ for $24 \mathrm{~h}$ (Fig. $2 \mathrm{a}-\mathrm{c}$ ). TEM images of the TX22 billet after pre-heating at $240^{\circ} \mathrm{C}$ for $0.5 \mathrm{~h}$ (before extrusion) are displayed, and tiny amount of precipitations can be observed (Fig. 2d and e). During the extrusion, some coarse MgSnCa and $\mathrm{Mg}_{2} \mathrm{Ca}$ phases on tens microns scales are sharply broken into micron sizes and distributed along the extrusion direction. After the extrusion processing, grain sizes of the as-extruded rods are extremely refined, as compared with those of as-solution billets (usually larger than $100 \mu \mathrm{m}$ ). Fig. 3 shows the band contrast images and inverse pole figure maps of as-extruded TX22 alloys extruded at different temperatures and ram speeds. In the TX22-220 alloy, most grains remain to be un-dynamically recrystallized (unDRXed), and numerous LAGBs disperse among the unDRXed grain interiors (Fig. 3a, f). Some DRXed grains are occasionally found to disperse in matrix. In this sense, both the DRXed grains and sub-grains are considered for grain size analysis, and the average grain size is estimated to be $\sim 0.32 \mu \mathrm{m}$ according to the band contrast image. The unDRXed grains keep the strong texture with $<10-10>$ axis of the $\mathrm{Mg}$ matrix parallel to ED, while the fine DRXed grains exhibit more randomized texture and two preferred orientations of both $<10$ -
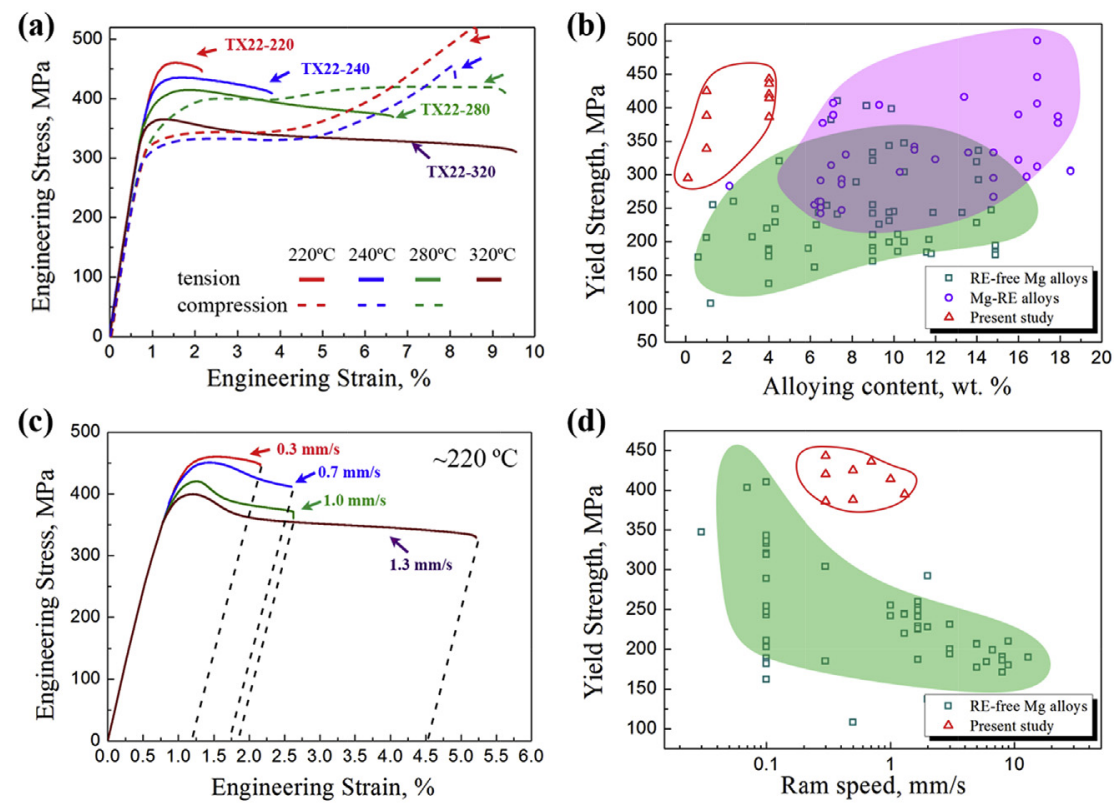

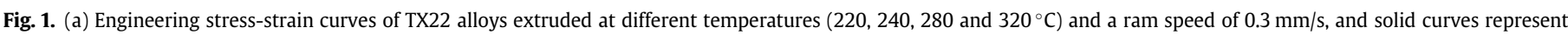

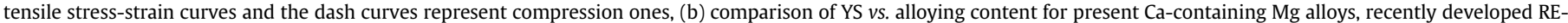

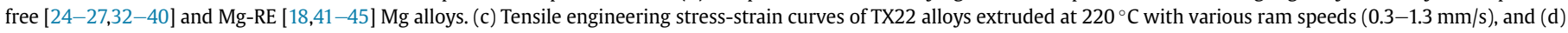
comparison of YS vs. ram speed for present Ca-containing Mg alloys extruded at various speeds and reported RE-free Mg alloys [24-27,32-40]. 
Table 1

YS, UTS, elongation and average grain size of as-extruded TX22 alloys (ram speed of $0.3 \mathrm{~mm} / \mathrm{s}$ ) under both tension and compression tests.

\begin{tabular}{|c|c|c|c|c|c|}
\hline Extruded samples & Yield strength (MPa) & Ultimate strength (MPa) & $\begin{array}{l}\text { Elongation } \\
(\%)\end{array}$ & Compression/tension yield ratio & Average grain size $(\mu \mathrm{m})$ \\
\hline TX22-220 & 443 (tension) & 460 (tension) & 1.2 (tension) & 0.72 & $0.32 \pm 0.15$ \\
\hline alloy & 319 (compression) & 518 (compression) & 7.5 (compression) & & \\
\hline TX22-240 & 420 (tension) & 435 (tension) & 3.0 (tension) & 0.73 & $0.48 \pm 0.20$ \\
\hline alloy & 308 (compression) & 452 (compression) & 7.0 (compression) & & \\
\hline TX22-280 & 386 (tension) & 414 (tension) & 5.8 (tension) & 0.90 & $0.65 \pm 0.23$ \\
\hline alloy & 349 (compression) & 415 (compression) & 8.3 (compression) & & \\
\hline TX22-320 & 358 & 365 & 8.9 & - & - \\
\hline
\end{tabular}
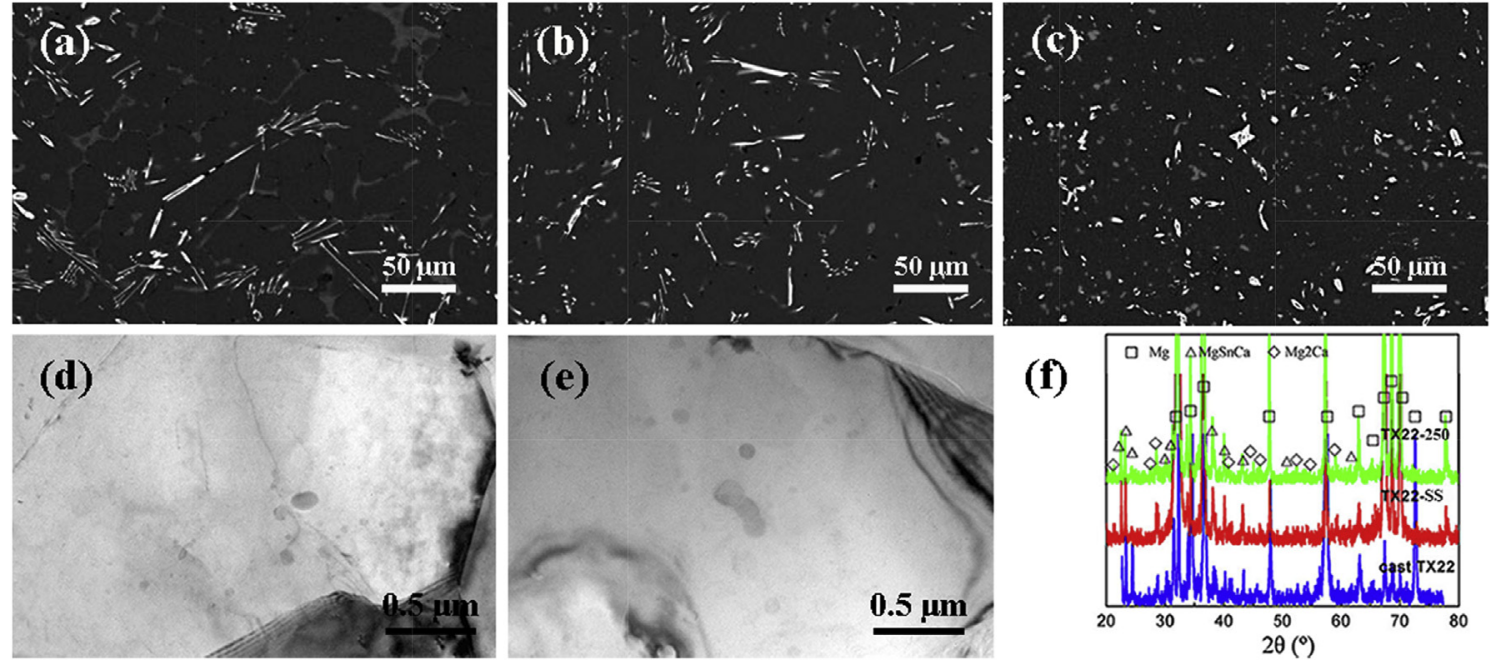

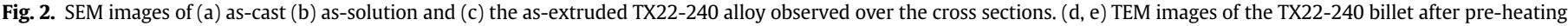
at $240{ }^{\circ} \mathrm{C}$ for $0.5 \mathrm{~h}$ (before extrusion). (f) XRD patterns of as-cast, as-solution and extruded TX22-240 alloy.

$10>/ /$ ED and $<11-20>/ /$ ED can be detected, as indicated in Fig. 3a and $\mathrm{f}$.

With increasing the extrusion temperature, the fraction of the unDRXed grains decreases from $~ 90 \%$ in TX22-220 to 52\% in TX22240 (Fig. 3b and g), and the near fully DRXed microstructure is obtained in the TX22-280 sample (Fig. $3 \mathrm{c}$ and h). Pole figures for both DRXed and unDRXed regions indicate that the unDRXed grains keep the fiber texture with $<10-10>/ / E D$. In contrast, the preferred orientations of the DRXed grains gradually rotate from $<10$ to $10>/ /$ ED to $<11-20>/ / E D$, and more randomized texture is generated with increasing of the extrusion temperature. The results are consistent with previous works of the texture components transition during DRX [46,47]. Higher extrusion temperature in the TX22-240 and TX22-280 alloys leads to certain grain growth, reaching $\sim 0.48 \mu \mathrm{m}$ and $\sim 0.65 \mu \mathrm{m}$ for the matrix grains, respectively. Nevertheless, the ultra-fine grain size of TX22-280 sample $(\sim 0.65 \mu \mathrm{m})$ is comparable with that obtained by severely deformed Mg-alloys such as the HPT-ed and aged Mg-Zn-Zr-Ca alloy $(\sim 0.77 \mu \mathrm{m})$ [48]. When increasing the ram speed, the high-speed extruded samples can maintain the ultra-fine grained microstructures, with the average grain size slightly increasing from $\sim 0.32 \mu \mathrm{m}$ at $0.3 \mathrm{~mm} / \mathrm{s}$ (TX22-220, Fig. 3a and f) to $\sim 0.39 \mu \mathrm{m}$ at $0.7 \mathrm{~mm} / \mathrm{s}$ (TX22-220-0.7, Fig. 3d and i) and $\sim 0.46 \mu \mathrm{m}$ at $1.0 \mathrm{~mm} / \mathrm{s}$ (TX22-220-1.0, Fig. 3e and j), respectively. It suggests that $\alpha-\mathrm{Mg}$ grains of the high-speed samples exhibit a high thermal stability, in spite of much more excessive frictional heat during extrusion.

TEM images of the as-extruded TX22 alloys are displayed in Fig. 4 and Fig. 5. Subgrains can be readily detected in the unDRXed region of TX22-220 alloy, and the LAGBs are indicated by the yellow arrows (Fig. 4a). Evidences of LAGBs could be found by comparing the selected area diffraction patterns (SADPs) between the adjacent subgrain lattices within an unDRXed grain $\left(\sim 3-5^{\circ}\right.$ in Fig. 5a). Moreover, the abundant nano-precipitates are found to be distributed homogeneously at both grain boundaries and in their interiors (Figs. 4b and 5b). The dynamically precipitated nanoprecipitates can be identified to be mainly the $\mathrm{Mg}_{2} \mathrm{Ca}$ phases, according to the SADPs and energy dispersive X-ray spectroscopy (EDS) mapping in Fig. $5 \mathrm{c}$ and $\mathrm{d}$. The orientation relationships between the $\mathrm{Mg}_{2} \mathrm{Ca}$ and $\mathrm{Mg}$ matrix is determined to be $[0001]_{\mathrm{Mg}} / /$ $[-12-10]_{\mathrm{Mg} 2 \mathrm{Ca}}$ and $(01-10)_{\mathrm{Mg}} / /(10-10)_{\mathrm{Mg} 2 \mathrm{Ca}}$. TX22-240 alloy exhibits more sharp DRXed grain boundaries and the nano-precipitates are homogeneously distributed (Fig. 4c and d). For the TX22-280 alloy, nano-precipitates are coarsened due to the higher extrusion temperature. Nevertheless, the nano-precipitates can also disperse nearby the grain boundaries, and the ultra-fine grains can be achieved (Fig. 4e and f).

Accompanied with the nano-precipitates, numerous linear structures lying on the (0001) planes of $\alpha$-Mg matrix are observed in the as-extruded TX22 alloys (Fig. 4b and d), and they are identified to be the non-basal dislocations under the two-beam diffraction condition of $\mathbf{g}=0002$ (Fig. 5b). The HAADF-STEM image further demonstrates that some of the line defects are in fact stacking faults (SFs) with the stacking sequence of ABABCACAC, and that the edge of these SFs is composed of Frank partial dislocations with Burgers vector of $1 / 6<2-203>$ (Fig. 5e). It was reported that the formation of such defects are associated with the dissociation of perfect $<c+a>$ dislocations [49,50]. Besides, it is hypothetical that the dislocations may provide preferred nucleation sites for the 

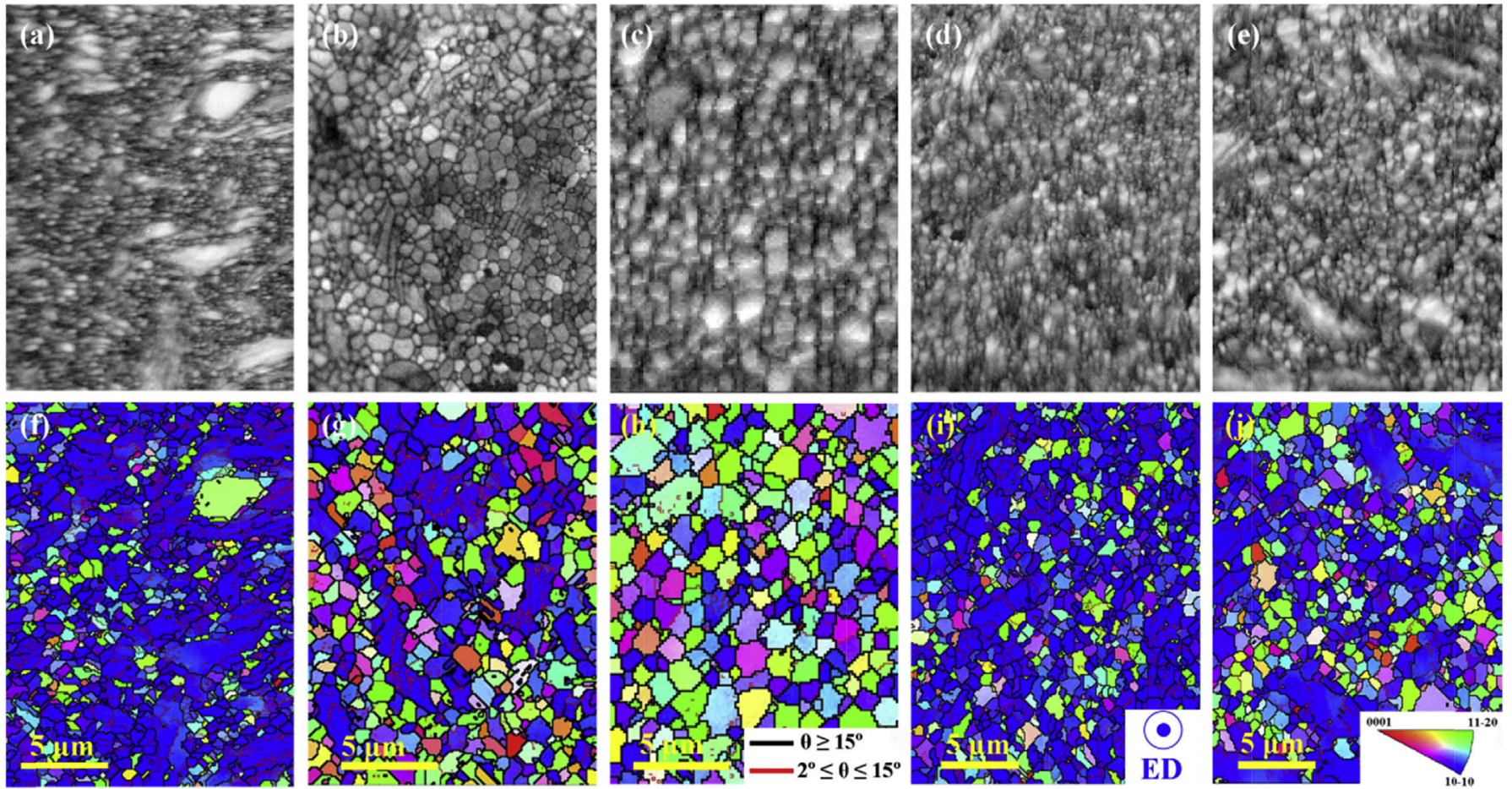

\section{Un-DRXed grains:}
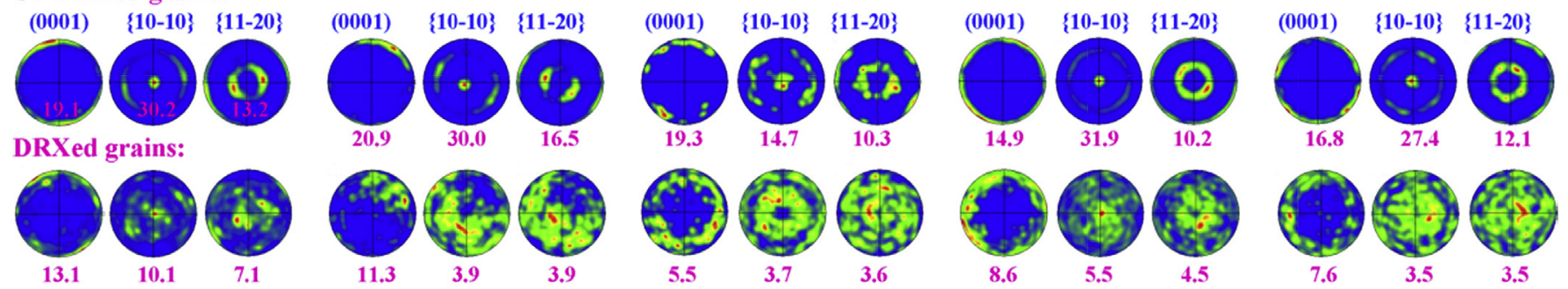

Fig. 3. (a-e) Band contrast images and ( $\mathrm{f}-\mathrm{j})$ inverse pole figure maps of the extruded TX22 alloy. (a, f) TX22-220, (b, j) TX22-240, (c, h) TX22-280 for the alloy extruded at $220-$ $280^{\circ} \mathrm{C}$ with the same ram speed of $0.3 \mathrm{~mm} / \mathrm{s}$; (d, i) TX22-220-0.7 and (e, j) TX22-220-1.0 for the alloy extruded at $220^{\circ} \mathrm{C}$ under ram speeds of $0.7 \mathrm{~mm} / \mathrm{s}$ and $1.0 \mathrm{~mm} / \mathrm{s}$, respectively. Pole figures for both DRXed and un-DRXed regions are presented with the maximum intensity noted below.
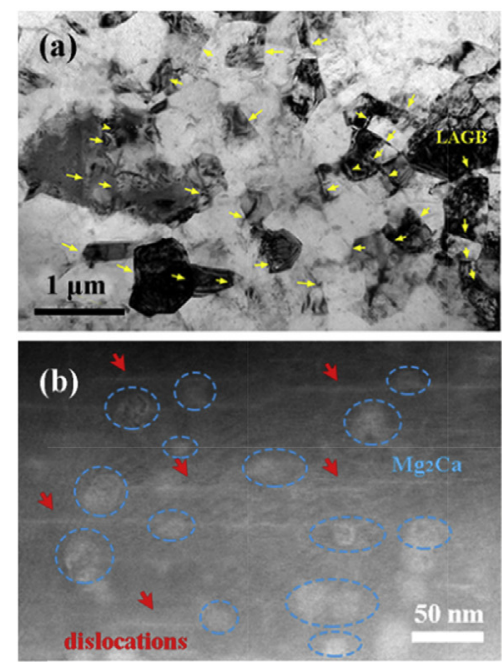
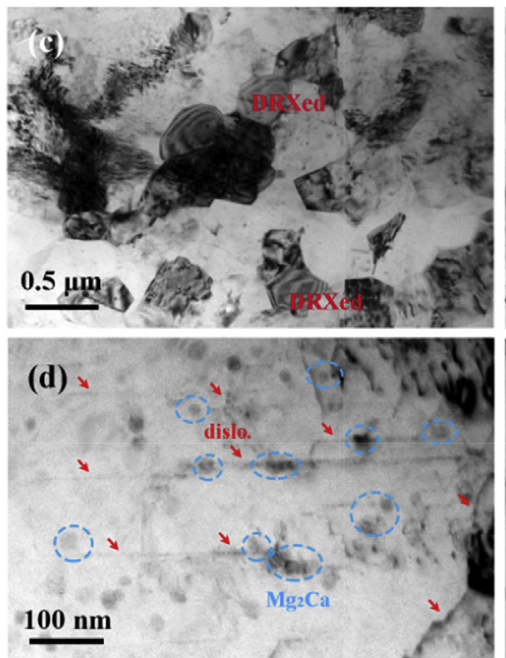
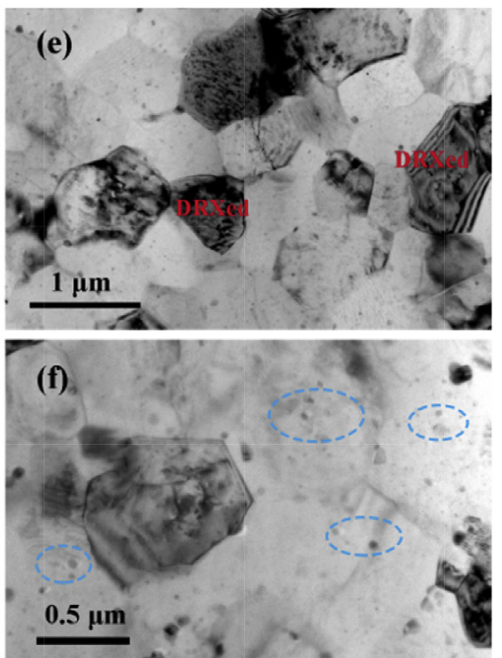

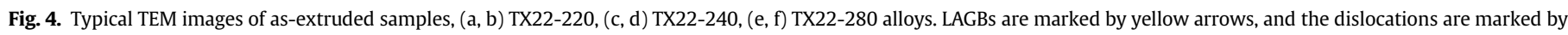

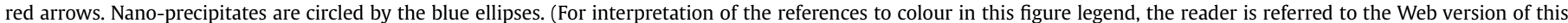
article.) 

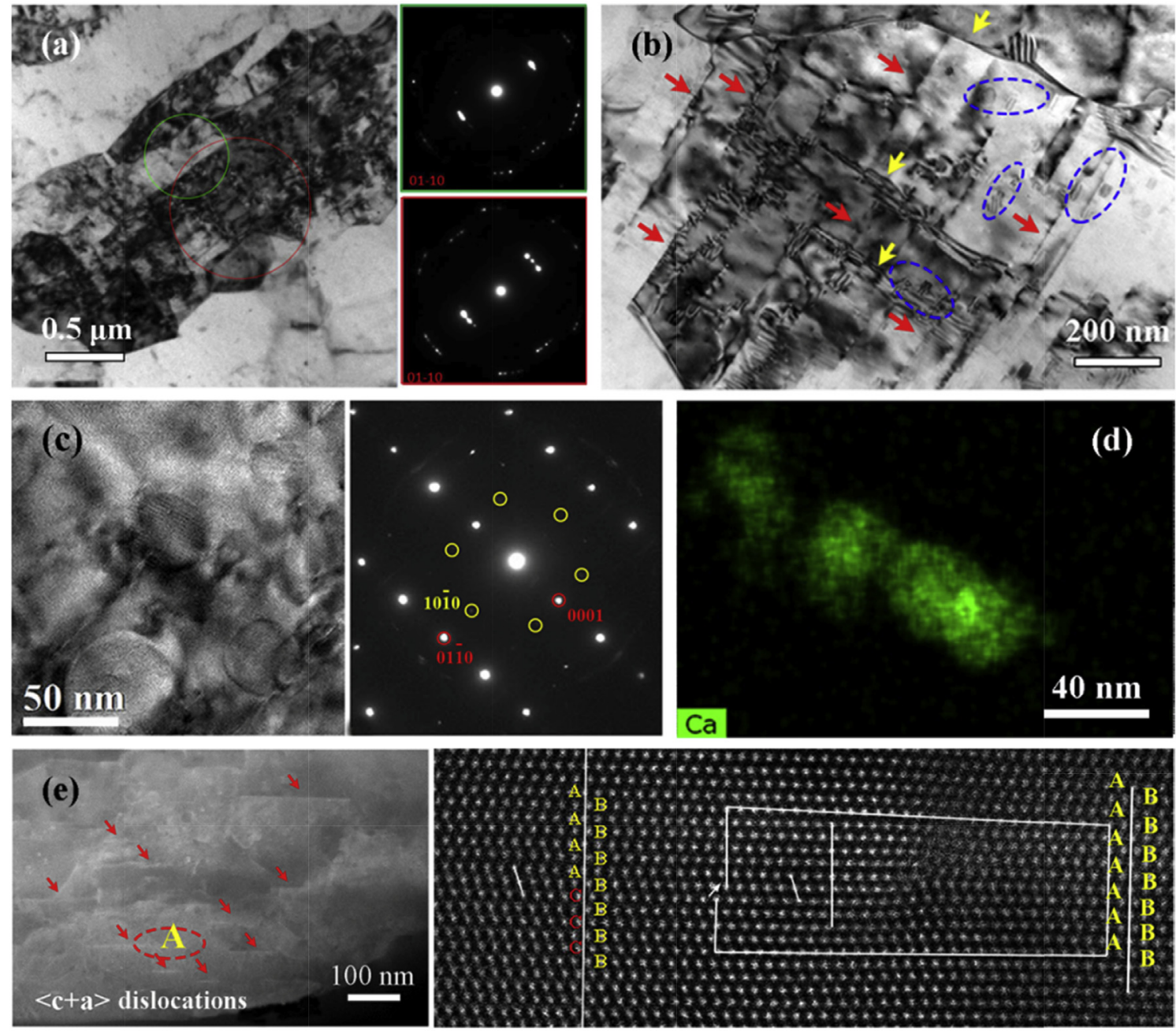

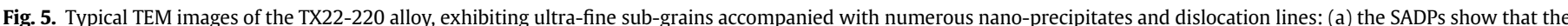

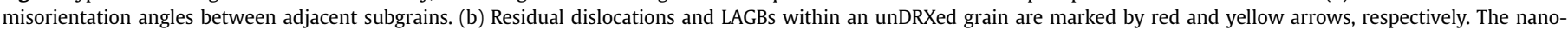

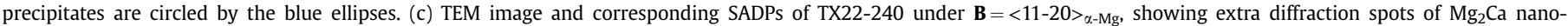

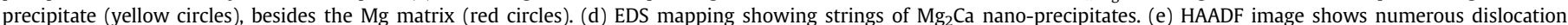

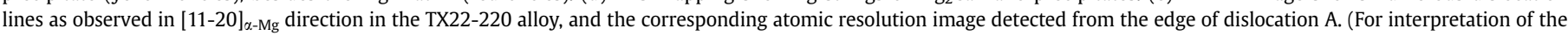
references to colour in this figure legend, the reader is referred to the Web version of this article.)

nano-precipitates, since large amounts of nano-precipitates are found to stay along or nearby the dislocation lines, as circled by the ellipses in Fig. $4 \mathrm{~b}$ and $d$.

\subsection{Microstructure evolutions during extrusion (EBSD results)}

To understand formation mechanism of the surprisingly refined grains in the present non-severely deformed $\mathrm{Mg}$ alloys, microstructure evolution in the representative TX22-240 billet extruded with a ram speed of $0.3 \mathrm{~mm} / \mathrm{s}$ was examined from different positions near the die exit, which was divided into stage I - III, and the corresponding inverse pole figures and pole figures images are shown in Fig. 6.

In the initial stage I, necklace-like fine DRXed grains in a size range of $1-6 \mu \mathrm{m}$ have been formed along the original HAGBs, Fig. 6a. A number of banded structures, as separated by the LAGBs, co-exist with the DRXed grains. Number fraction of LAGBs is estimated to be $\sim 55 \%$, as displayed in Fig. 7 . With continuously shifting to stage II, the banded structures formed in the early stage I are intersected by higher density of LAGBs, and a more complex microstructure can be generated (Fig. 6b). This includes the ultra- fine necklace-like grains formed along HAGBs, i.e., discontinuous DRX (DDRX in area A), continuous recrystallized grains in grain interiors (CDRX in area $\mathrm{B}$ ), and also the coarse as-deformed grains (area C). As compared with stage I, both the DRX fraction and LAGB density (line density of $\sim 8.5 \%$, see Fig. 7 ) in stage II have increased due to the more severe deformation. When evolving into stage III near the die nozzle, a large number of recrystallized grains in size of $0.1-0.3 \mu \mathrm{m}$ are present continuously within the deformed regions, exhibiting typical DRX texture of $<11-20>/ / E D$ (Fig. 6c). In spite of that, majority of the grains still remains to be unDRXed and numerous LAGBs can be detected in the as-deformed grain interiors. The highest line density of LAGBs $(\sim 9.5 \%)$ is generated in grain interiors of the stage III sample, while the fraction of LAGBs significantly decreases to be $\sim 40 \%$ in stage III. Finally, the $\alpha-\mathrm{Mg}$ matrix grains of the TX22-240 alloy shows the similar mixture microstructure with both fine DRXed grains $(0.3-0.6 \mu \mathrm{m})$ and ultra-fine sub-grains $(0.1-0.3 \mu \mathrm{m})$ (Fig. 3). The fraction of LAGBs decreases to $\sim 20 \%$ in the TX22-240 alloy, and continuously decreases to $\sim 7 \%$ in the TX22-280 alloy with more sufficiently DRXed microstructure (Fig. 7). 

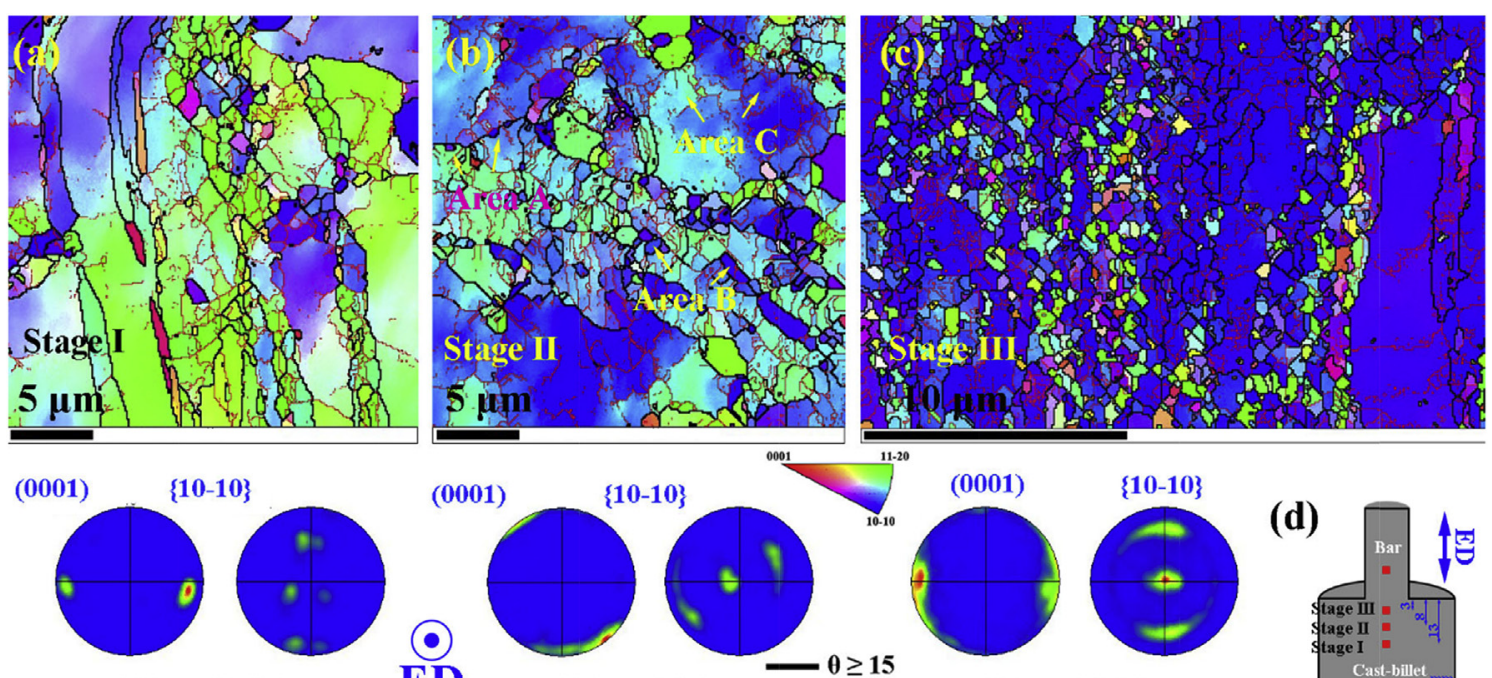

$\operatorname{Max}=\mathbf{5 6 . 3 8}$
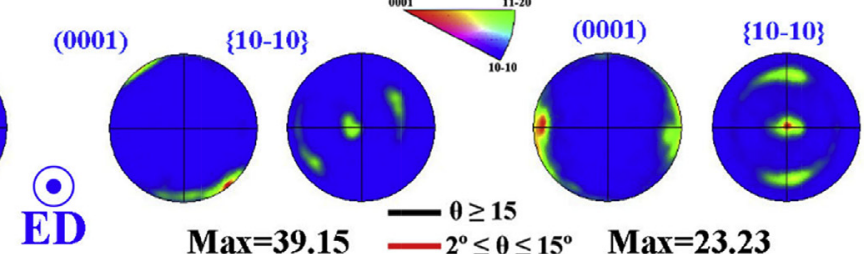

(d)

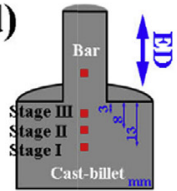

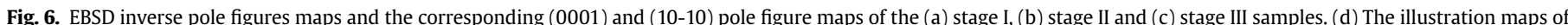

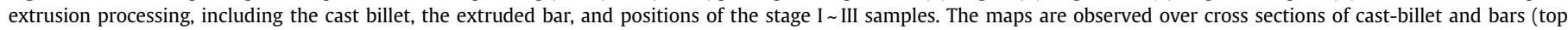
surface), and ED represents the extrusion direction.

(a)

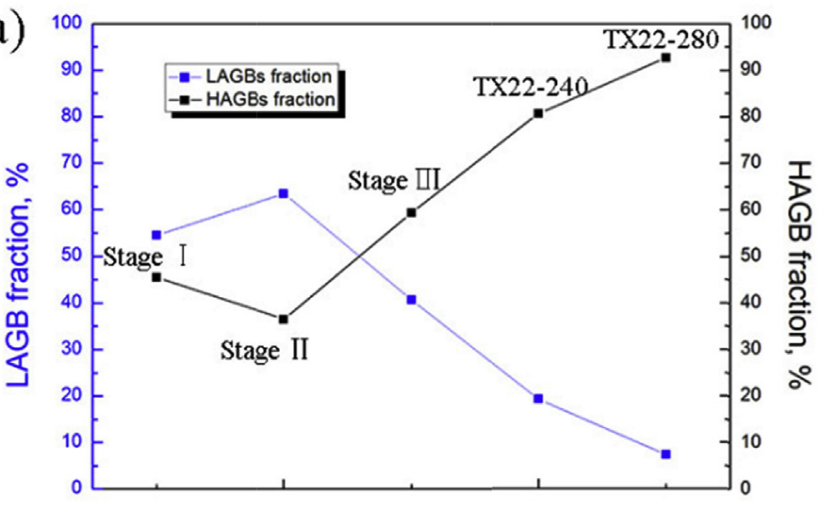

(b)

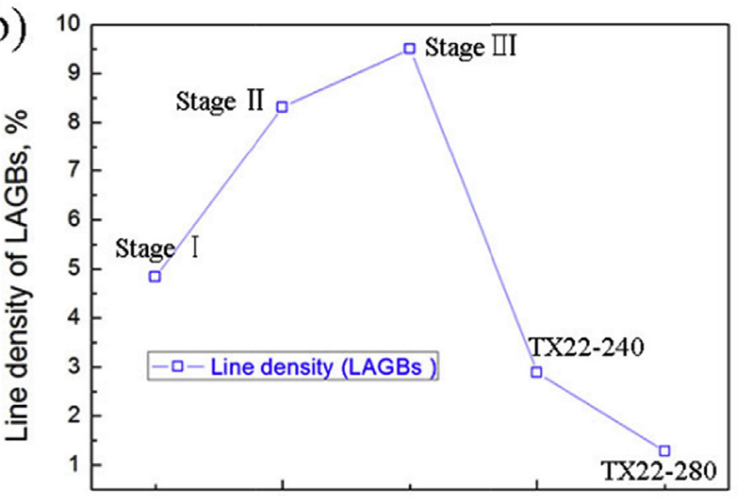

Fig. 7. (a) Fractions of both LAGBs and HAGBs and (b) the absolute line-densities of LAGBs in different stages of extrusion in the TX22-240 billet, including the as-extruded TX22-240 and TX22-280 alloys.

\subsection{TEM characterization of stage I sample}

To further clarify formation mechanism of the ultrafine grains, TEM observations were carried on the stage I III samples in TX22240 billet. Fig. 8a shows that well-defined cell structures, composed of the low density of dislocations, are formed in stage I.
Occasionally, some residual basal and non-basal dislocations can be detected within grain interiors, as revealed by the two-beam diffraction images in Fig. 8b and c. Nevertheless, the total density of dislocations is low, which may result from the dynamic generation and recovery of dislocations during the early stage of extrusion.

\subsection{TEM characterization of stage II sample}

With shifting to stage II, the high density pyramidal dislocations are readily induced, resulting in the severe lattice distortion. For example, both the grey and dark contrasts are found to appear in the limited region of an unDRXed grain under the incident beam direction of $B=<10-10\rangle$ (Fig. 9a), which indicates variations of the lattice orientations in grain interiors. In the bright field TEM images, regions close to zone axis will show the dark contrast, while regions away from the zone axis orientation appear grey. Consequently, the grain boundaries and interiors become fuzzy, resulting from inhomogeneous distributions of dislocations and the high local lattice strain. More evidences of internal lattice distortions can be found in Fig. 9b, and some tiny DRXed grains have already been formed due to the high internal strains.

Simultaneously, some curved and/or straight subgrain boundaries have been formed in the stage II sample, as indicated by dashlines and asterisks in Fig. 9c. By careful examination, the array of pyramidal dislocations are observed to intersect with the LAGBs, but do not go across the boundaries. The dislocation walls (subsubstructures) start to transform into the subgrains at this stage. Moreover, it is observed that the subgrain formation can only be detected in the limited regions nearby the as-deformed grain boundaries. Besides, profuse nano-phases are dynamically precipitated, which were identified to be $\mathrm{Mg}_{2} \mathrm{Ca}$. As seen from Fig. 9d, considerable amounts of nano-particles disperse along the dislocation lines. Several nano-particles connect with each other and locate along the same line defects. It suggests that the dislocations can promote formation of the nano-precipitations. By comparing the number density of phases with those in stage I, it can be known that the nano-precipitates are mainly formed in stage II. That is, the dynamic precipitation occurs much faster and earlier than the fully DRX process, and the pre-induced precipitation would necessarily affect the subsequent formations of DRXed grains. 

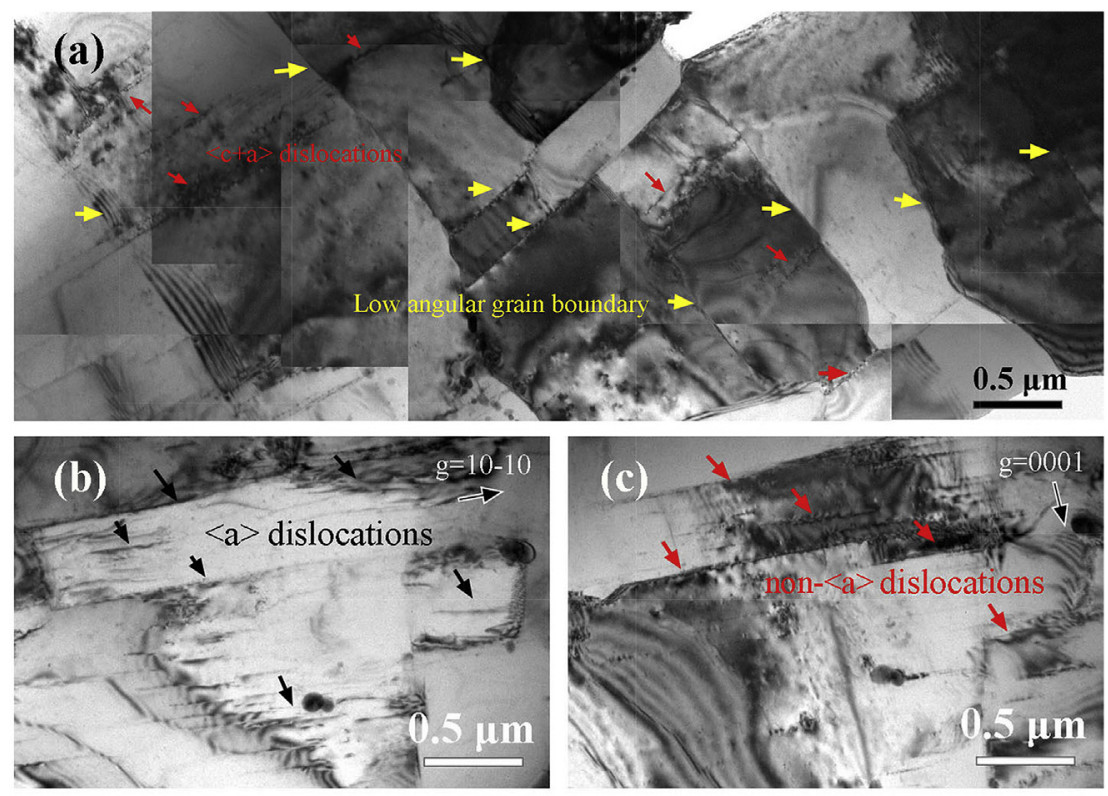

Fig. 8. (a) TEM image of the cell structures formed in the stage I sample. TEM images detected from the stage I sample under two-beam diffraction conditions of (b) $\mathbf{g}=10-10$ and (c) $\mathbf{g}=0002$.
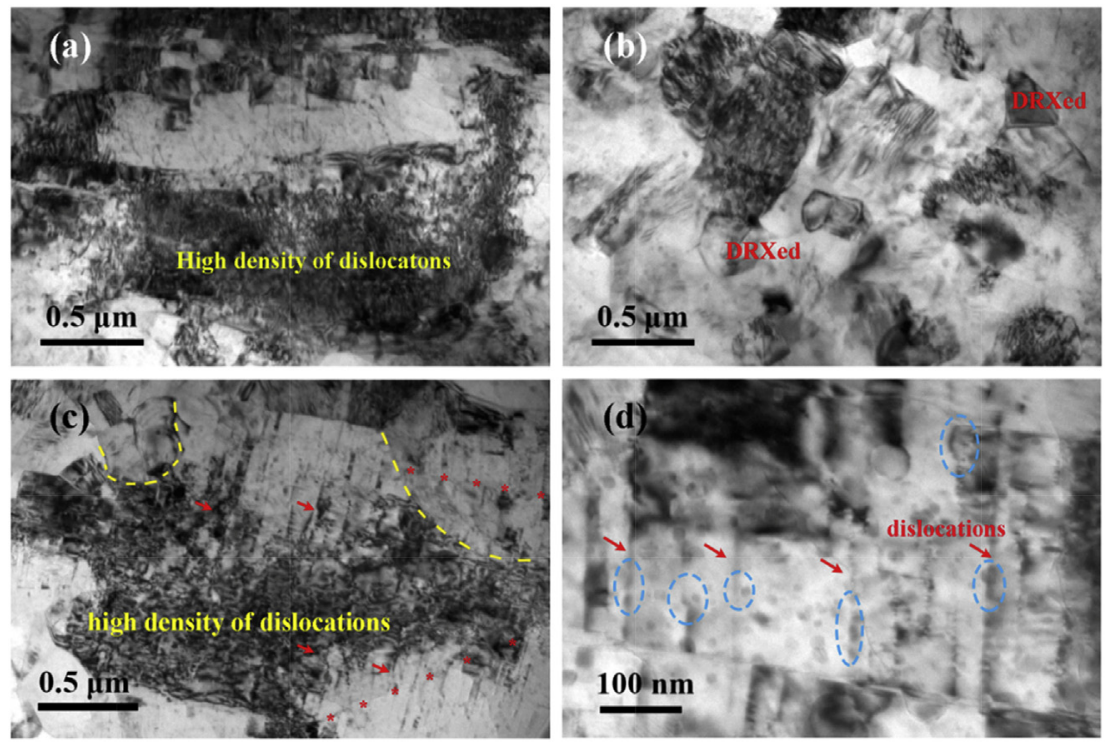

Fig. 9. TEM images in the stage II: (a, b) un-DRXed grain under the incident beam direction of $B=\langle 10-10\rangle$, and nucleation of DRXed grains. (c, d) Some subgrains have been formed nearby grain boundaries of the as-deformed grains. Pyramidal dislocations and LAGBs are indicated by the red arrows and yellow dot-lines, respectively. (For interpretation of the references to colour in this figure legend, the reader is referred to the Web version of this article.)

\subsection{TEM characterizations of stage III and as-extruded samples}

In stage III, the majority of the grain remains to be unDRXed, and the LAGBs are indicated by the asterisks in Fig. 10a. Arrays of the dislocations (marked by red arrows) are found to interact with the LAGBs. More importantly, it is expected that the LAGBs and the residual dislocations play the critical role in generating the potential nuclei of recrystallization. Some nuclei have transformed to the subgrains and occupy the original grain interiors in the manner of CDRX, as marked by dashed line in Fig. 10a. More interestingly, HAADF images in Fig. 10b indicate that the considerable solutes are enriched along both the dislocations and LAGBs. EDS mapping in the TX22-240 sample confirms considerable solute Ca atoms are found to be enriched at the LAGBs, nearby which the $\mathrm{Mg}_{2} \mathrm{Ca}$ nanoprecipitates are profusely detected (Fig. 10c). Further observations show that the LAGBs are actually composed of a number of pyramidal dislocation (Fig. 10f and g). The TEM images over a wider region can be found in Fig. 10d, showing the concurrent appearances of precipitates, dislocations and subgrains. Residual dislocation density becomes lower than those in the stage II, while the distribution of dislocations is still inhomogeneous. The subgrains, which result from dislocation movement during extrusion, would contribute to enhance the nucleation rates of the DRXed grains. Readily, some DRXed grains with clear HAGBs have already been formed nearby the subgrains (Fig. 10e).

With shifting to as-extruded bar, more fully DRXed grains are 

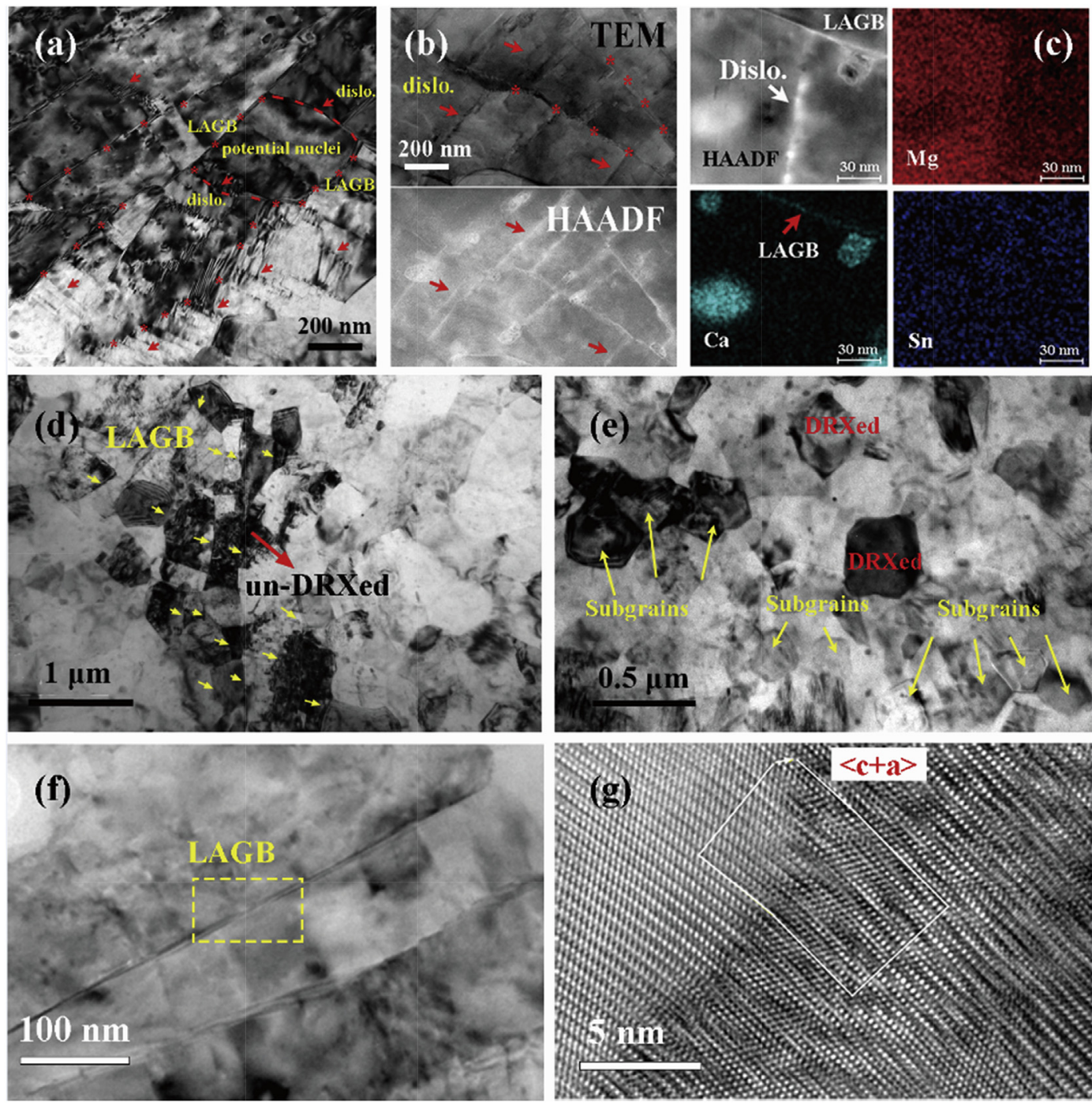

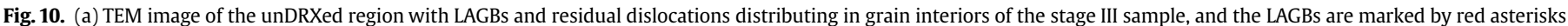

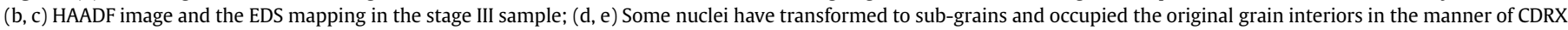

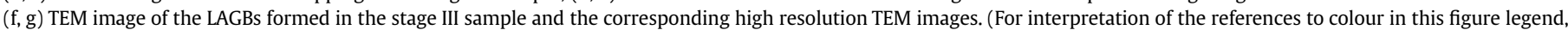
the reader is referred to the Web version of this article.)

found (Figs. 3 and 11). Nevertheless, the certain amount of the unDRXed grains can still co-exist with the fine DRXed grains (Fig. 11a). HAADF images show that the Ca segregation at the LAGBs, residual dislocations, as well as the $\mathrm{Mg}_{2} \mathrm{Ca}$ nano-precipitates can be detected in the as-extruded TX22-240 alloy (Fig. 11b).

\section{Discussion}

In the present Mg-Sn-Ca alloy system, the microstructures of asextruded alloys have been extensively examined by the detailed EBSD and TEM analysis. The TX22-240 sample is selected as the
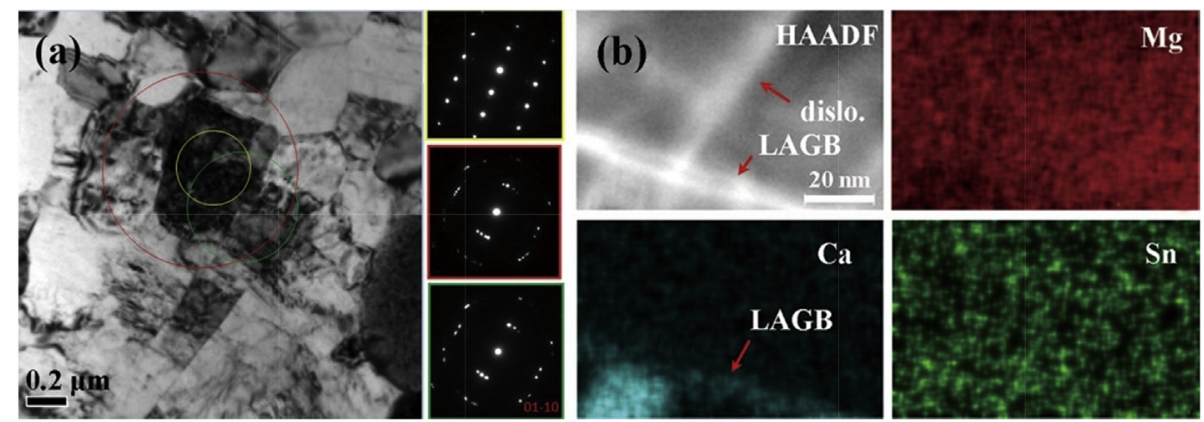

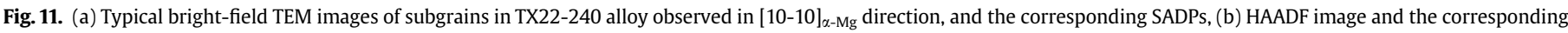
EDS mapping in the TX22-240 alloy. 
typical alloy to study the microstructure evolution during extrusion and clarify the formation mechanism of surprisingly ultra-fine matrix grains.

\subsection{Dynamic recovery and recrystallization during extrusion}

The as-extruded TX22 alloys can be composed of either the unDRXed grain microstructure, the bimodal grain microstructure, or the fully DRXed grain microstructure depending on the extrusion parameters. It is observed that both the profuse dislocations and dynamic nano-precipitation play the key role in forming the subgrains during the extrusion of Mg-Sn-Ca alloys. High number density of the subgrains and their restricted transformation into the DRXed grains pinned by the partitioned solutes lead to the significant grain refinement.

At the beginning stage I, accumulation of the dislocations is difficult due to the limited strain. Dynamic recovery plays the major role in inducing rearrangement of dislocations and the gradual formation of cell microstructures. The grain boundaries are mainly composed of the lamellar structures, which resemble the lamellar sub-grains generated in ECAPed $\mathrm{Al}-1 \mathrm{Mg}$ alloy due to the rearrangement of mobile dislocations [51]. In this stage, new grains nucleate at periphery of the previous grain boundaries, which follows the typical manner of discontinuous DRX process.

With shifting to stage II, the high densities of both dislocations and precipitates are present simultaneously. The discontinuous nucleation of subgrains along grain boundaries is evidently observed, while the grain interiors with tangled dislocations keep in the un-DRXed state. The high line density of LAGBs in this stage (Fig. 7) can be partially ascribed to the high internal strain since it is expected that the misorientation within one unDRXed grain would easily exceed $2^{\circ}$ under this large lattice-torsion strain. More importantly, it is believed that the certain grain boundary energy would provide the driving force for the LAGBs to develop into HAGBs. This is also the reason why fine DRXed grains are gradually formed during extrusion. When subjected to further extrusion (stage III), both regions of the grain boundaries and interiors would undergo nucleation of the subgrains. In this stage, certain numbers of LAGBs are added by the newly formed subgrain boundaries, rather than the lattice torsion boundaries in stage II. The absolute line density of LAGBs would essentially increase (Fig. 7). Interestingly, the percentage of LAGBs decreases in stage III, as compared with stage II. It suggests that a certain percentage of LAGBs has transformed into HAGBs and DRXed grains are formed. Consequently, the original coarse grains are gradually evolved into a mixture of fine grains bounded by HAGBs and unDRXed grains composed of subgrains in the stage III and as-extruded alloys.

\subsection{Dynamic activation of dislocations and solute partitioning}

As mentioned above, both activations of the dislocations and solute partitioning effectively contribute to refining grains of TX22 alloy down to sub-micron size. It is noted that the segregated solutes are mainly the Ca atoms as confirmed by the EDS results (Figs. 10 and 11), and Sn solubility is low at the extrusion temperatures since most of $\mathrm{Sn}$ atoms are consumed by the coarse as-cast MgSnCa phase (Fig. 2) [29]. Consequently, the robust activation of the high density of dislocations may be ascribed to the solute $\mathrm{Ca}$ dissolved in the $\alpha-\mathrm{Mg}$ matrix, which agrees well with previous studies [52-54]. On the other hand, Ca element may also act to prevent the annihilation and reduce mobility of the dislocations, as a result of the strong dislocation-solute interaction [55]. Reduction in mobility of dislocation will suppress the rate of recovery and recrystallization, leading to accumulations of the defects. The high density of dislocations would rearrange to form the plenty of subgrains at both the grain boundaries and interiors during extrusion. More recently, Zhu et al. [56] proposed a formation mechanism of LAGBs in wrought Mg alloys, and claimed that the I1 type stacking faults, which are the same as the segment of dislocations mentioned above, can facilitate the formation of LAGBs via dislocation movements and interplays. In the present $\mathrm{Mg}-\mathrm{Sn}-\mathrm{Ca}$ alloys, the array of dissociated dislocations is also observed to intersect with LAGBs, as shown in Fig. 10, which may suggest that the dislocation walls transform into LAGBs via the similar mechanism of polygonization [46,56]. More evidences can be deduced from the atomic structure of LAGBs composing a number of pyramidal dislocations.

Moreover, the dynamic precipitations occur robustly with the activation of dislocations. In fact, the severe dynamic precipitation requires both the high-speed atom diffusions and the presence of sufficient high density defects. The high density of dislocations can be generated during the low temperature extrusion, as shown in Fig. 9. The dislocation lines represent the high-energy regions, and the stress field around the defects contributes to increase the driving force for mass transfer. For example, the dislocations pipes can supply fast diffusion path for solute clusters [57]. Thus, the nano-precipitations nearby the dislocation lines can be effectively promoted. On the other hand, the dynamic precipitations are formed prior to the fully DRX. Presence of the nano-precipitates can continuously restrict growth of the subgrains and DRXed grains. However, different viewpoints have been proposed in regarding the effect of nano-phases on grain refinement during DRX. It is usually accepted in Mg alloys that the nano-phases would pin dislocations and then subgrains can be eventually nucleated. For example, previous work on Mg-6.2Zn-0.4Ag-0.16Ca-0.6Zr (in wt.\%) alloy claimed the significant effect of $\mathrm{Zr}$ addition on the formation of subgrains, where the presence of $\mathrm{Mg}(\mathrm{Zn}, \mathrm{Zr})$ precipitates was considered to pin the mobile dislocations [46]. The other study in $\mathrm{Al}$ alloys suggested that precipitates would facilitate retention of high density of dislocations by both promoting their generations and pinning the movements [58]. In this work, it is demonstrated that the dislocation activations are controlled by solute concentration dissolved in $\mathrm{Mg}$ matrix and the formation of nano-phases are dynamically induced by dislocations.

Besides that, the enrichment of Ca atoms at the LAGBs occurs readily in present samples, and the ultrafine-grain instability can be greatly suppressed by solute drag mechanism [59]. The recent works also demonstrate that some particular solutes (such as RE and $\mathrm{Zn}$ ) can be attracted to the particular defects, such as twin boundaries, grain boundaries and stacking faults in Mg alloys, and the solute segregations are usually considered to be energetically favorable $[50,60]$. Similarly, the segregation of Ca atoms to the LAGBs can also reduce the total energy. As a result, the solute $\mathrm{Ca}$ segregation can block the motion of GBs and retard the process for transformations from sub-grains into the DRXed grains, finally contributing to the formation of ultra-fine matrix grains. Although the high-speed extruded samples have excessive frictional heat, a similar pinning effect should also operate, which can enhance the thermal stability of the grain boundaries and lead to ultra-fine grains, e.g., in the TX22-220-0.7 (-1.0) alloy (Fig. 3).

\subsection{Mechanism of the ultra-high strength}

We have engineered the new RE-free Mg alloy with superior mechanical properties to reach a higher strength limit with much lower alloying content. The alloy features the complex structures of (i) submicron matrix grains, (ii) the residual dislocations, (iii) the homogeneously distributed nano-precipitates, and (iv) the solute enrichment at LAGBs. The high strength originated from the above microstructures would be analyzed as follows. 
Firstly, it is well accepted that the submicron grain size can account for the strength increment by restricting dislocation generation and movement, as depicted by Hall-Petch (HP) relationship $\left(\sigma_{y s}=\sigma_{0}+k_{y} d^{-0.5}\right)$, where $d$ is the average grain diameter, $\sigma_{0}$ is the friction stress and $k_{y}$ is the HP slope. Previous studies showed that the HP relationship for $\mathrm{Mg}$ alloys is dependent of grain size and texture $[28,61]$. The friction stress and HP slope are directly related to the activated slip systems and CRSS of the Mg matrix [28]. The soft orientation leads to a lower friction stress and lower HP slope, while the hard orientation results in larger strengthening. A number of studies have confirmed the prismatic-dominant-slip deformation mode in $\mathrm{Mg}$ alloys with strong fiber texture, via EPSC modeling and in situ neutron diffraction [62,63]. Yuan et al. [61] found $\sigma_{0}$ and $k_{y}$ equal to $103 \mathrm{MPa}$ and $236 \mathrm{MPa} \mu \mathrm{m}^{0.5}$, respectively, for the prismatic-slip dominant AZ31 alloy with an average grain size ranging from 1.4 to $10.2 \mu \mathrm{m}$. Recently, S.M. Razavi et al. [28] found that in the prismatic-slip dominated AZ31 alloy, with the grain size reduced below $1 \mu \mathrm{m}$, the $\sigma_{0}$ and $k_{y}$ values changed to $208 \mathrm{MPa}$ and $90 \mathrm{MPa} \mu \mathrm{m}^{0.5}$, respectively. In regard to the present TX22 samples with strong fiber texture, the $\sigma_{0}$ of $208 \mathrm{MPa}$ and $k_{y}$ values of $90 \mathrm{MPa} \mu \mathrm{m}^{0.5}$ can be used to estimate the strengthening contribution due to grain refinement, by ignoring the solute strengthening difference between present samples and AZ31 alloy.

More importantly, it is well known that LAGBs with misorientation lower than $15^{\circ}$ possess lower resistance to slip transmission, thus contributing poor strengthening effects as compared with HAGBs. As shown in Figs. 3 and 6, most sub-grain boundaries are LAGBs. Therefore, using above grain size analysis method, high fraction of grains with LAGB is included in grain size measurement (especially for TX22-220 alloy) and strengthening prediction. Such analysis may overestimate the strengthening contribution from grain refinement. In this sense, a modified Hall-Petch relationship is given as following,

$\sigma_{y s}=\sigma_{0}+\sigma_{L A G B}+\sigma_{H A G B}+\Delta \sigma_{\text {Orowan }}$

where the $\sigma_{L A G B}$ and $\sigma_{H A G B}$ present the strengthening contributions from LAGBs and HAGBs respectively, and the $\Delta \sigma_{\text {Orowan }}$ stands for the potential strengthening increment due to the Orowan mechanism.

Accordingly, contribution of LAGBs to yield strength of asextruded TX22 samples can be evaluated by the dislocation strengthening mechanism, since the LAGB mainly consists of dislocations. The dislocation strengthening effect can be correlated with the dislocation density as following [64],

$\sigma_{L A G B}=M \alpha G b \sqrt{\rho_{0}+\rho_{L A G B}}$

where $M$ is the average Taylor factor (i.e., 2.5 in present case with strong fiber texture) [62], $\alpha$ is a constant $(=0.2), G$ is the shear modulus ( $\approx 17 \mathrm{GPa}$ ), $b$ is the Burgers vector of the gliding dislocations $(|b|=0.32 \mathrm{~nm}), \rho_{0}$ is the dislocation density estimated from the well-annealed materials $\left(\rho_{0} \leq 10^{12} \mathrm{~m}^{-2}\right), \rho_{\text {LAGB }}$ is the dislocation located in the LAGBs. As indicted in Fig. 7, the change in fraction of LAGBs under different extrusion conditions would necessarily result in variations of the dislocation density, and $\rho_{\text {LAGB }}$ can be estimated by Ref. [64],

$\rho_{L A G B}=\frac{3(1-f) \bar{\theta}_{L A G B}}{b d}$

where $f$ is the number fraction of HAGBs, and $\theta(-)_{\text {LAGB }}$ is the average misorientation of LAGBs, as listed in Table 2. $\theta(-)_{\text {LAGB }}$ is evaluated from the misorientation distribution data (misorientation vs. number fraction), as illustrated in Ref. [64]. As a result, contribution from LAGBs to strengthening can be given as,
$\sigma_{L A G B}=M \alpha G b \sqrt{\rho_{0}+\frac{3(1-f) \bar{\theta}_{L A G B}}{b d}}$

In addition, contribution of HAGBs to strengthening follows the HP relationship,

$\sigma_{H A G B}=k_{y}\left(\frac{d}{f}\right)^{-1 / 2}$

By substituting parameters above, strengthening from LAGBs and HAGBs can be calculated separately, as listed in Table 2.

Secondly, the high number density of nano-phases in the present prismatic-slip dominant alloys can impart strengthening effect via Orowan mechanism. The additional stress required for $<\mathrm{a}>$ dislocations to overcome the precipitates on the prismatic plane should be considered in the present case. For simplicity, precipitates are considered to be bypassed by dislocations, so the Orowan mechanism determines the strength increment [65,66],

$\Delta \tau_{\text {Orowan }}=\left(\frac{G b}{2 \pi \sqrt{1-\nu}}\right)\left(\frac{1}{\lambda}\right) \log \left(\frac{D_{p}}{r_{0}}\right)$

where $\Delta \tau_{\text {Orowan }}$ is the increase in the CRSS due to precipitate strengthening, $\nu$ is the Poison ratio $(\approx 0.3), \lambda$ is the effective interparticle spacing along the particular slip plane. $D_{p}$ is the mean planar diameter of the particle on the slip plane, and $r_{0}$ is the dislocation core radius, which is approximated to be the magnitude of $|b|$. According to the parameters listed in Table 2, including $D_{p}$ and $\lambda$, the CRSS increment could be calculated. Contribution of the Orowan hardening to the YS increment can be estimated, by considering the average Taylor factor $M(\sim 2.5)$. The YS increment due to the Orowan hardening $\left(\Delta \sigma_{\text {Orowan }}\right)$ in TX22-220, TX22-240 and TX22-280 samples are calculated to be $\sim 52 \mathrm{MPa}, \sim 46 \mathrm{MPa}$ and $\sim 39 \mathrm{MPa}$, respectively (Table 2).

Finally, solute segregation along the LAGBs must possess certain dragging effect on the dislocation motion to account for the high strength. Actually, solute segregation or clustering have been reported in several RE-containing $\mathrm{Mg}$ alloys and are related to strengthening. For example, the superior mechanical properties of $\mathrm{Mg}-\mathrm{Zn}-\mathrm{Y}$ alloy are not only attributed to the LPSO phases, but also a similar phenomenon of Suzuki segregation [50]. Nie et al. reported the periodic segregation of $\mathrm{Gd} / \mathrm{Zn}$ atoms on various twin boundaries in $\mathrm{Mg}$ alloys, which exerted a stronger pinning effect on twin boundaries migration, hence, a larger strengthening effect [60]. By accounting for the contribution from the friction stress $\sigma_{0}$, YSs of the TX22-220, TX22-240 and TX22-280 alloys are predicted to be $\sim 456 \mathrm{MPa}, \sim 410 \mathrm{MPa}$ and $\sim 373 \mathrm{MPa}$, respectively. The slight deviation of the calculated YSs from the measured values may be ascribed to the HP parameters adopted from AZ series Mg alloys, and/or the dislocation densities deduced from LAGBs fractions.

\subsection{Novelty of present Ca-containing $\mathrm{Mg}$ alloys}

Some other RE-free high-strength Mg alloys were reported, which was recently reviewed by Pan et al. [67]. For example, extraordinary high strength (400 MPa) can been achieved in $\mathrm{Mg}$ 8Al-0.5Zn alloy via the slow speed extrusion and/or multi-step extrusion and rolling process [32-34,68]. However, it should be noted that such excellent mechanical properties are obtained by a more expensive or complicated processing procedure, as compared with the TX22 alloys developed in present work. In the Mg-Sn system, YSs of the wrought alloy are in the range of 200-320 MPa, due to the limited ability of grain refinement during processing [24-27]. Moreover, the total amount of solute addition 
Table 2

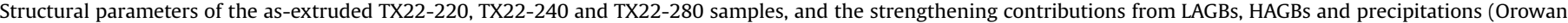
hardening).

\begin{tabular}{|c|c|c|c|c|c|c|c|c|c|}
\hline \multirow{2}{*}{$\begin{array}{l}\text { Extruded } \\
\text { Samples }\end{array}$} & \multicolumn{3}{|c|}{ HAGB strengthening } & \multicolumn{3}{|c|}{ LAGB strengthening } & \multicolumn{3}{|c|}{ Orowan strengthening } \\
\hline & $d(\mu \mathrm{m})$ & $f(\%)$ & $\sigma_{H A G B}(\mathrm{MPa})$ & $\begin{array}{l}\theta(-)_{L A G B} \\
\left({ }^{\circ}\right)\end{array}$ & $\begin{array}{l}\rho_{L A G B} \\
\left(10^{14} \mathrm{~m}^{-2}\right)\end{array}$ & $\begin{array}{l}\sigma_{L A G B} \\
(\mathrm{MPa})\end{array}$ & $D_{p}(\mathrm{~nm})$ & $\begin{array}{l}\lambda \\
(\mathrm{nm})\end{array}$ & $\begin{array}{l}\Delta \sigma_{\text {Orowan }} \\
(\mathrm{MPa})\end{array}$ \\
\hline TX22-220 & $\sim 0.32$ & 65.2 & $\sim 128$ & $\sim 6.1$ & $\sim 6.2$ & $\sim 68$ & $\sim 30$ & $\sim 100$ & $\sim 52$ \\
\hline TX22-240 & $\sim 0.48$ & 80.7 & $\sim 116$ & $\sim 6.0$ & $\sim 2.2$ & $\sim 40$ & $\sim 40$ & $\sim 120$ & $\sim 46$ \\
\hline TX22-280 & $\sim 0.65$ & 92.7 & 107 & $\sim 5.8$ & $\sim 0.6$ & $\sim 19$ & $\sim 55$ & $\sim 150$ & $\sim 39$ \\
\hline
\end{tabular}

would usually exceed $8 \mathrm{wt} \%$, which is not cost-effective for their applications. Recently, Sasaki et al. developed a new Mg-5.4Sn4.2Zn-2.0Al-0.2Mn (wt.\%) alloy via nano-precipitations, while the highest YS is still lower than $350 \mathrm{MPa}$ [31]. Besides, there have been lots of attempts to develop the novel Mg-Ca based alloy. However, the main works focused on the texture weakening due to the $\mathrm{Ca}$ addition. For example, in the Mg-Ca-Zn alloy, the excellent ductility can be achieved and the YS is usually lower than $300 \mathrm{MPa}$ [69]. In contrast, the present work shows that it is possible to obtain ultrahigh strength in Mg-Sn-Ca alloys via low alloying addition and cheap processing cost.

On the other hand, the present work shows that high strength of the TX22 alloys can be maintained under relatively high extrusion speed of $0.7-1.0 \mathrm{~mm} / \mathrm{s}$, since the average grain size can keep as fine as $0.39-0.46 \mu \mathrm{m}$. In spite of that, extrusion speed used to produce TX22 alloy is still low, as compared with that of the Al alloys (in the magnitude of $10 \mathrm{~mm} / \mathrm{s}$, ram speed [30]). Thus, it is necessary to further extrude TX22 alloys at much higher speed. Fortunately, absolute strengths of the TX22 alloys are much higher than those of the high-speed extruded $\mathrm{Al}$ and $\mathrm{Mg}$ alloys (<300 MPa). Decreasing rate of YSs with increasing ram-speed is also lower as compared with other RE-free Mg alloys (Fig. 1d). Moreover, Nakata et al. [30] has recently developed a new $\mathrm{Mg}$-Al-Ca-Mn alloy which has similar strength with 6000 series $\mathrm{Al}$ alloys, under the same high extrusion speed ( $>10 \mathrm{~mm} / \mathrm{s}$ ). Consequently, it is considered possible to obtain high strength in present $\mathrm{Mg}$-Sn-Ca alloys under relatively high ram-speed, which will be the future work.

By the way, the present TX22 alloys exhibit lower asymmetry than conventional Mg alloys, as listed in Table 1. In spite of that, there still exists a large gap between the tension and compression yield strengths, $100 \mathrm{MPa}$, especially in the TX22-220 and TX22240 alloys. The large strength gap can be attributed to the strong fiber texture, where the $\{10-12\}$ twinning could be more favorable for compression along the ED than tension along the $\operatorname{ED}[14,15]$. The compressive curves of the two samples with concave shape also indicate that $\{10-12\}$ twinning could have larger contribution on compressive yielding than on tension (Fig. 1). Thus, the compressive yielding is usually lower in strongly textured $\mathrm{Mg}$ alloys, as compared with tension. With the increasing extrusion temperature to $280^{\circ} \mathrm{C}$, the yield asymmetry is remarkably decreased (with asymmetry ratio of 0.9 ). It can be ascribed to the weak fiber texture in the TX22-280 alloy (Fig. 3) and the contribution of $\{10-12\}$ twinning on compressive yielding can be largely reduced. Change of compressive curves from concave shape in TX22-220 to parabolic shape in TX22-280 further confirms this result (Fig. 1). Therefore, the developed alloy can serve as an attractive candidate for industrial applications.

\section{Conclusions}

In summary, we have produced a light-weight Mg-2Sn-2Ca alloy with low alloying contents. A notably high yield strength and acceptable ductility have been obtained from the as-extruded $\mathrm{Mg}$ 2Sn-2Ca alloy, and some main conclusions can be made as follows:
1) The as-extruded TX22 alloys exhibit the highest YS of $443 \mathrm{MPa}$ and UTS of $460 \mathrm{MPa}$, which exceed the known strength limits of RE-free Mg alloys, and are even comparable with those of reported RE-containing Mg alloys. The present Ca-containing Mg alloys are in a region of high strength and low alloying. Moreover, the present Mg alloys can keep at a high-strength level under the relatively high extrusion speeds.

2) The Ca addition promotes accumulations of the pyramidal dislocations in TX22 alloys, which eventually transform into the LAGBs. The dynamic recrystallization operates via either DDRX mechanism in the early stage or the CDRX mechanism in the later stage of extrusion. More importantly, it is demonstrated that the LAGBs and the residual dislocations play the critical role in generating the potential nuclei of recrystallization during extrusion of present Mg alloys.

3) The enrichment of Ca atoms at the LAGBs occurs readily in present samples, nearby which the $\mathrm{Mg}_{2} \mathrm{Ca}$ nano-precipitates are profusely detected. The solute $\mathrm{Ca}$ segregation and nanoprecipitates can block the motion of LAGBs and retard the process for transformation from the sub-grains into the DRXed grains, finally contributing to the formation of submicron matrix grains.

4) The ultra-high strengths of present samples are associated with submicron-sized grains, mono-dispersive nano-precipitates, residual dislocations and solute Ca segregation at many LAGBs. Ultra-fine grain size of the high-speed extruded TX22 alloys effectively guarantees the excellent yield strength.

Overall, the findings lead to a new and controllable alloy design strategy towards ultra-high strength Mg-alloys, which involves a combination of induced dynamic solute partitioning and a relatively high volume fraction of mono-dispersive nano-precipitates, to restrict the growth of dynamically recrystallized grains. The simple and low content of alloying elements, the relatively low extrusion temperature and high extrusion speed, and the route of one-step extrusion, are expected to open ever-bright prospects for fabricating high performance Mg products for larger-scale industrial applications.

\section{Acknowledgements}

The authors acknowledge financial support from National Key Research and Development Program of China (2016YFB0701200), and National Natural Science Foundation of China (Nos. 51525101, U1610253, 51371046, 51501032 and 51131009). The authors acknowledge the help of EBSD characterizations from Xusheng Yang (Chongqing University of Technology) and the discussions with Jia She (Chongqing University) and Bo Song (Southwest University).

\section{References}

[1] S. You, Y. Huang, K.U. Kainer, N. Hort, Recent research and developments on wrought magnesium alloys, J. Mag. Alloys 5 (3) (2017) 239-253.

[2] X. Liu, Y. Liu, B. Jin, Y. Lu, J. Lu, Microstructure evolution and mechanical 
properties of a SMATed Mg alloy under in situ SEM tensile testing, J. Mater. Sci. Technol. 33 (3) (2017) 224-230.

[3] S. Jiang, H. Wang, Y. Wu, X. Liu, H. Chen, M. Yao, B. Gault, D. Ponge, D. Raabe, A. Hirata, Ultrastrong steel via minimal lattice misfit and high-density nanoprecipitation, Nature 544 (7651) (2017) 460-464.

[4] L. Lu, Y. Shen, X. Chen, L. Qian, K. Lu, Ultrahigh strength and high electrical conductivity in copper, Science 304 (5669) (2004) 422-426.

[5] B. He, B. Hu, H. Yen, G. Cheng, Z. Wang, H. Luo, M. Huang, High dislocation density-induced large ductility in deformed and partitioned steels, Science 357 (6355) (2017) 1029-1032.

[6] G. Wu, K.-C. Chan, L. Zhu, L. Sun, J. Lu, Dual-phase nanostructuring as a route to high-strength magnesium alloys, Nature 545 (7652) (2017) 80-83.

[7] J.-F. Nie, Precipitation and hardening in magnesium alloys, Metall. Mater. Trans. A 43 (11) (2012) 3891-3939.

[8] L.-Y. Chen, J.-Q. Xu, H. Choi, M. Pozuelo, X. Ma, S. Bhowmick, J.-M. Yang, S. Mathaudhu, X.-C. Li, Processing and properties of magnesium containing a dense uniform dispersion of nanoparticles, Nature 528 (7583) (2015) 539.

[9] H. Fu, B. Ge, Y. Xin, R. Wu, C. Fernandez, J. Huang, Q. Peng, Achieving high strength and ductility in magnesium alloys via densely hierarchical double contraction nanotwins, Nano Lett. 17 (10) (2017) 6117-6241.

[10] M. Yamasaki, T. Anan, S. Yoshimoto, Y. Kawamura, Mechanical properties of warm-extruded Mg-Zn-Gd alloy with coherent 14H long periodicstacking ordered structure precipitate, Scripta Mater. 25 (2005) 799-803.

[11] T. Homma, N. Kunito, S. Kamado, Fabrication of extraordinary high-strength magnesium alloy by hot extrusion, Scripta Mater. 61 (2009) 644-647.

[12] S. Biswas, S. Singh Dhinwal, S. Suwas, Room-temperature equal channel angular extrusion of pure magnesium, Acta Mater. 58 (9) (2010) 3247-3261.

[13] K. Edalati, A. Yamamoto, Z. Horita, T. Ishihara, High-pressure torsion of pure magnesium: evolution of mechanical properties, microstructures and hydrogen storage capacity with equivalent strain, Scripta Mater. 64 (2011) 880-883.

[14] R.G. Li, J.F. Nie, G.J. Huang, Y.C. Xin, Q. Liu, Development of high-strength magnesium alloys via combined processes of extrusion, rolling and ageing, Scripta Mater. 64 (2011) 950-953.

[15] B. Song, R. Xin, G. Chen, X. Zhang, Q. Liu, Improving tensile and compressive properties of magnesium alloy plates by pre-cold rolling, Scripta Mater. 66 (12) (2012) 1061-1064.

[16] A. Inoue, Y. Kawamura, M. Matsushita, K. Hayashi, J. Koike, Novel hexagonal structure and ultrahigh strength of magnesium solid solution in the Mg-Zn-Y system, J. Mater. Res. 16 (07) (2001) 1894-1900.

[17] Q. Wang, J. Chen, Z. Zhao, S. He, Microstructure and super high strength of cast Mg-8.5Gd-2.3Y-1.8Ag-0.4Zr alloy, Mater. Sci. Eng., A 528 (1) (2010) 323-328.

[18] Z. Yu, C. Xu, J. Meng, X. Zhang, S. Kamado, Effects of pre-annealing on microstructure and mechanical properties of as-extruded $\mathrm{Mg}$-Gd-Y-Zn-Zr alloy, J. Alloy. Comp. 729 (2017) 627-637.

[19] X.F. Huang, W.Z. Zhang, Improved age-hardening behavior of Mg-Sn-Mn alloy by addition of Ag and Zn, Mater. Sci. Eng., A 552 (2012) 211-221.

[20] J.C. Oh, T. Ohkubo, T. Mukai, K. Hono, TEM and 3DAP characterization of an age-hardened Mg-Ca-Zn alloy, Scripta Mater. 53 (2005) 675-679.

[21] M. Lentz, M. Risse, N. Schaefer, W. Reimers, I. Beyerlein, Strength and ductility with $\{10-11\}-\{10-12\}$ double twinning in a magnesium alloy, Nat. Commun. 7 (2016), 11068

[22] X.-F. Huang, W.-Z. Zhang, Improved age-hardening behavior of Mg-Sn-Mn alloy by addition of Ag and Zn, Mater. Sci. Eng., A 552 (2012) 211-221.

[23] J. Nie, B. Muddle, Precipitation hardening of Mg-Ca (-Zn) alloys, Scripta Mater. 37 (10) (1997) 1475-1481.

[24] W.L. Cheng, H.S. Kim, B.S. You, B.H. Koo, S.S. Park, Strength and ductility of novel $\mathrm{Mg}-8 \mathrm{Sn}-1 \mathrm{Al}-1 \mathrm{Zn}$ alloys extruded at different speeds, Mater. Lett. 65 (11) (2011) 1525-1527.

[25] T.T. Sasaki, K. Yamamoto, T. Honma, S. Kamado, K. Hono, A high-strength $\mathrm{Mg}-\mathrm{Sn}-\mathrm{Zn}-\mathrm{Al}$ alloy extruded at low temperature, Scripta Mater. 59 (10) (2008) 1111-1114.

[26] F.R. Elsayed, T.T. Sasaki, T. Ohkubo, H. Takahashi, S.W. Xu, S. Kamado, K. Hono, Effect of extrusion conditions on microstructure and mechanical properties of microalloyed Mg-Sn-Al-Zn alloys, Mater. Sci. Eng., A 588 (0) (2013) 318-328.

[27] S. Park, B. You, Low-temperature superplasticity of extruded Mg-Sn-Al-Zn alloy, Scripta Mater. 65 (3) (2011) 202-205.

[28] S.M. Razavi, D.C. Foley, I. Karaman, K.T. Hartwig, O. Duygulu, L.J. Kecskes, S.N. Mathaudhu, V.H. Hammond, Effect of grain size on prismatic slip in Mg-3Al-1Zn alloy, Scripta Mater. 67 (5) (2012) 439-442.

[29] H. Pan, G. Qin, M. Xu, H. Fu, Y. Ren, F. Pan, Z. Gao, C. Zhao, Q. Yang, J. She, B. Song, Enhancing mechanical properties of $\mathrm{Mg}-\mathrm{Sn}$ alloys by combining addition of Ca and Zn, Mater. Des. 83 (0) (2015) 736-744.

[30] T. Nakata, C. Xu, R. Ajima, K. Shimizu, S. Hanaki, T.T. Sasaki, L. Ma, K. Hono, S. Kamado, Strong and ductile age-hardening Mg-Al-Ca-Mn alloy that can be extruded as fast as aluminum alloys, Acta Mater. 130 (2017) 261-270.

[31] T. Sasaki, F. Elsayed, T. Nakata, T. Ohkubo, S. Kamado, K. Hono, Strong and ductile heat-treatable $\mathrm{Mg}-\mathrm{Sn}-\mathrm{Zn}-\mathrm{Al}$ wrought alloys, Acta Mater. 99 (2015) $176-186$.

[32] J. Wang, R. Liu, T. Luo, Y. Yan, A high strength and ductility Mg-Zn-Al-Cu-Mn magensium alloy, Mater. Des. 47 (2013) 746-749.

[33] H. Yu, S.H. Park, B.S. You, Development of extraordinary high-strength $\mathrm{Mg}-8 \mathrm{Al}-0.5 \mathrm{Zn}$ alloy via a low temperature and slow speed extrusion, Mater. Sci. Eng., A 610 (0) (2014) 445-449.
[34] B. Kim, C.H. Park, H.S. Kim, B.S. You, S.S. Park, Grain refinement and improved tensile properties of $\mathrm{Mg}-3 \mathrm{Al}-1 \mathrm{Zn}$ alloy processed by low-temperature indirect extrusion, Scripta Mater. 76 (0) (2014) 21-24.

[35] W. Kim, S. Hong, Y. Kim, Enhancement of the strain hardening ability in ultrafine grained Mg alloys with high strength, Scripta Mater. 67 (7) (2012) 689-692.

[36] J.-w. Kang, X.-f. Sun, K.-k. Deng, F.-j. Xu, X. Zhang, Y. Bai, High strength Mg-9Al serial alloy processed by slow extrusion, Mater. Sci. Eng., A 697 (2017) 211-216.

[37] T. Bhattacharjee, T. Nakata, T. Sasaki, S. Kamado, K. Hono, Effect of microalloyed $\mathrm{Zr}$ on the extruded microstructure of $\mathrm{Mg}-6.2 \mathrm{Zn}$-based alloys, Scripta Mater. 90 (2014) 37-40.

[38] B.P. Zhang, L. Geng, L.J. Huang, X.X. Zhang, C.C. Dong, Enhanced mechanical properties in fine-grained $\mathrm{Mg}-1 \mathrm{Zn}-0.5 \mathrm{Ca}$ alloys prepared by extrusion at different temperatures, Scripta Mater. 63 (2010) 1024-1027.

[39] S. Xu, K. Oh-Ishi, S. Kamado, F. Uchida, T. Homma, K. Hono, High-strength extruded Mg-Al-Ca-Mn alloy, Scripta Mater. 65 (3) (2011) 269-272.

[40] H. Zhang, D. Zhang, C. Ma, S. Guo, Improving mechanical properties and corrosion resistance of $\mathrm{Mg}$ 6Zn Mn magnesium alloy by rapid solidification, Mater. Lett. 92 (2013) 45-48.

[41] Z. Yu, C. Xu, J. Meng, S. Kamado, Microstructure evolution and mechanical properties of a high strength Mg-11.7 Gd-4.9 Y-0.3 Zr (wt\%) alloy prepared by pre-deformation annealing, hot extrusion and ageing, Mater. Sci. Eng., A 703 (2017) 348-358.

[42] W. Rong, Y. Zhang, Y. Wu, Y. Chen, T. Tang, L. Peng, D. Li, Fabrication of highstrength Mg-Gd-Zn-Zr alloys via differential-thermal extrusion, Mater. Char. 131 (2017) 380-387.

[43] M. Jiang, C. Xu, T. Nakata, H. Yan, R. Chen, S. Kamado, Enhancing strength and ductility of Mg-Zn-Gd alloy via slow-speed extrusion combined with preforging, J. Alloy. Comp. 694 (2017) 1214-1223.

[44] C. Xu, M. Zheng, S. Xu, K. Wu, E. Wang, G. Fan, S. Kamado, Improving strength and ductility of $\mathrm{Mg}-\mathrm{Gd}-\mathrm{Y}-\mathrm{Zn}-\mathrm{Zr}$ alloy simultaneously via extrusion, hot rolling and ageing, Mater. Sci. Eng., A 643 (2015) 137-141.

[45] X. Liu, Z. Zhang, W. Hu, Q. Le, L. Bao, J. Cui, Effects of extrusion speed on the microstructure and mechanical properties of Mg 9Gd 3Y $1.5 \mathrm{Zn} 0.8 \mathrm{Zr}$ alloy, J. Mater. Sci. Technol. 32 (4) (2016) 313-319.

[46] K. Oh-ishi, C.L. Mendis, T. Homma, S. Kamado, T. Ohkubo, K. Hono, Bimodally grained microstructure development during hot extrusion of $\mathrm{Mg}-2.4 \mathrm{Zn}$ 0.1Ag-0.1Ca-0.16Zr (at.\%) alloys, Acta Mater. 57 (2009) 5593-5604.

[47] C.D. Barrett, A. Imandoust, A.L. Oppedal, K. Inal, M.A. Tschopp, H. El Kadiri, Effect of grain boundaries on texture formation during dynamic recrystallization of magnesium alloys, Acta Mater. 128 (2017) 270-283.

[48] R. Zheng, T. Bhattacharjee, A. Shibata, T. Sasaki, K. Hono, M. Joshi, N. Tsuji, Simultaneously enhanced strength and ductility of Mg-Zn-Zr-Ca alloy with fully recrystallized ultrafine grained structures, Scripta Mater. 131 (2017) $1-5$.

[49] S.R. Agnew, L. Capolungo, C.A. Calho, Connections between the basal I1 growth fault and $<\mathrm{c}+\mathrm{a}>$ dislocations, Acta Mater. 82 (2015) 255-265.

[50] Z. Yang, M.F. Chisholm, G. Duscher, X. Ma, S.J. Pennycook, Direct observation of dislocation dissociation and Suzuki segregation in a Mg-Zn-Y alloy by aberration-corrected scanning transmission electron microscopyalloy, Acta Mater. 61 (2013) 350-359.

[51] C. Xu, Z. Horita, T. Langdon, Microstructural evolution in an aluminum solid solution alloy processed by ECAP, Mater. Sci. Eng., A 528 (18) (2011) 6059-6065.

[52] A. Moitra, S.-G. Kim, M. Horstemeyer, Solute effect on the $<\mathrm{a}+\mathrm{c}>$ dislocation nucleation mechanism in magnesium, Acta Mater. 75 (2014) 106-112.

[53] Y. Wu, S. Li, Z. Ding, W. Liu, Y. Zhao, Y. Zhu, Effect of charge redistribution factor on stacking-fault energies of Mg-based binary alloys, Scripta Mater. 112 (2016) 101-105.

[54] H. Pan, H. Fu, B. Song, Y. Ren, C. Zhao, G. Qin, Formation of profuse dislocations in deformed calcium-containing magnesium alloys, Phil. Mag. Lett. 96 (7) (2016) 249-255.

[55] H.W. Zhang, K. Lu, R. Pippan, X. Huang, N. Hansen, Enhancement of strength and stability of nanostructured Ni by small amounts of solutes, Scripta Mater. 65 (6) (2011) 481-484.

[56] S.Q. Zhu, S.P. Ringer, On the role of twinning and stacking faults on the crystal plasticity and grain refinement in magnesium alloys, Acta Mater. 144 (Supplement C) (2018) 365-375.

[57] D. Blavette, E. Cadel, A. Fraczkiewicz, A. Menand, Three-dimensional atomicscale imaging of impurity segregation to line defects, Science 286 (5448) (1999) 2317-2319.

[58] Y. Shen, R. Guan, Z. Zhao, R. Misra, Ultrafine-grained Al-0.2 Sc-0.1 Zr alloy: the mechanistic contribution of nano-sized precipitates on grain refinement during the novel process of accumulative continuous extrusion, Acta Mater 100 (2015) 247-255.

[59] D.A. Basha, R. Sahara, H. Somekawa, J.M. Rosalie, A. Singh, K. Tsuchiya, Interfacial segregation induced by severe plastic deformation in a $\mathrm{Mg}-\mathrm{Zn}-\mathrm{Y}$ alloy, Scripta Mater. 124 (2016) 169-173.

[60] J.F. Nie, Y.M. Zhu, J.Z. Liu, X.Y. Fang, Periodic Segregation of Solute Atoms in fully coherent twin boundaries, Science 340 (957-960) (2013).

[61] W. Yuan, S.K. Panigrahi, J.Q. Su, R.S. Mishra, Influence of grain size and texture on Hall-Petch relationship for a magnesium alloy, Scripta Mater. 65 (11) (2011) 994-997.

[62] J. Jain, P. Cizek, W.J. Poole, M.R. Barnett, Precipitate characteristics and thei 
effect on the prismatic-slip-dominated deformation behaviour of an $\mathrm{Mg}-6 \mathrm{Zn}$ alloy, Acta Mater. 61 (11) (2013) 4091-4102.

[63] M.D. Nave, M.R. Barnett, Microstructures and textures of pure magnesium deformed in plane-strain compression, Scripta Mater. 51 (9) (2004) 881-885.

[64] P. Luo, D.T. McDonald, W. Xu, S. Palanisamy, M.S. Dargusch, K. Xia, A modified Hall-Petch relationship in ultrafine-grained titanium recycled from chips by equal channel angular pressing, Scripta Mater. 66 (10) (2012) 785-788.

[65] J.D. Robson, N. Stanford, M.R. Barnett, Effect of precipitate shape on slip and twinning in magnesium alloys, Acta Mater. 59 (5) (2011) 1945-1956.

[66] J. Nie, Effects of precipitate shape and orientation on dispersion strengthening in magnesium alloys, Scripta Mater. 48 (8) (2003) 1009-1015.

[67] H. Pan, Y. Ren, H. Fu, H. Zhao, L. Wang, X. Meng, G. Oin, Recent developments in rare-earth free wrought magnesium alloys having high strength: a review, J. Alloy. Comp. 663 (2016) 321-331.

[68] S.Q. Zhu, H.G. Yan, J.H. Chen, Y.Z. Wu, Y.G. Du, X.Z. Liao, Fabrication of Mg-AlZn-Mn alloy sheets with homogeneous fine-grained structures using high strain-rate rolling in a wide temperature range, Mater. Sci. Eng. A 559 (2013) $765-772$.

[69] S.W. Xu, K. Oh-ishi, H. Sunohara, S. Kamado, Extruded Mg-Zn-Ca-Mn alloys with low yield anisotropy, Mater. Sci. Eng., A 558 (0) (2012) 356-365. 